\title{
Testing the necessity of transient spikes in the storm time ring current drivers
}

\author{
Michael W. Liemohn, ${ }^{1}$ Raluca Ilie, ${ }^{2}$ Natalia Y. Ganushkina, ${ }^{1,3}$ Aaron J. Ridley, ${ }^{1}$ \\ Janet U. Kozyra, ${ }^{1}$ Michelle F. Thomsen, ${ }^{2}$ and Joseph E. Borovsky ${ }^{2}$ \\ Received 8 July 2010; revised 7 February 2011; accepted 10 February 2011; published 22 April 2011.
}

[1] Inner magnetospheric numerical simulations of the 17 April 2002 storm are conducted to explore the importance of transient spikes in the driving parameters at controlling the strength of the storm time ring current. The two main factors considered in this study are convection electric field strength and nightside plasma boundary condition. These quantities were smoothed and/or despiked across intervals of 20-180 min. It is found that the spikes contribute linearly to the ring current total energy content. Exceptions to this finding include too much resulting ring current after despiking or smoothing (relative to a linear response). This indicates that at best the relationship is linear and, if the timing of transient spikes in one driving parameter is not coincident with high values in the other main driving parameter, then the response is sublinear (that is, the transient spikes could be less effective than long-time duration increases in the input parameters).

Citation: Liemohn, M. W., R. Ilie, N. Y. Ganushkina, A. J. Ridley, J. U. Kozyra, M. F. Thomsen, and J. E. Borovsky (2011), Testing the necessity of transient spikes in the storm time ring current drivers, J. Geophys. Res., 116, A04226, doi:10.1029/2010JA015914.

\section{Introduction}

[2] The ring current has two main drivers: (1) its source population in the near-Earth plasma sheet and (2) the magnetospheric electric field that pushes these particles into the inner magnetosphere. It has been shown that elevated values for both of these drivers are necessary to create a strong storm time ring current [e.g., Kozyra and Liemohn, 2003; Liemohn and Khazanov, 2005, and references therein]. If either one is dramatically reduced in strength, then the ring current will undergo a recovery, despite the intensity of the other driver, as was shown for an intense magnetic storm [Kozyra et al., 2002] and with a parametric study of idealized storm driving conditions [Liemohn and Kozyra, 2005].

[3] Time series plots of these driving conditions for the ring current, however, reveal many transient spikes in these quantities throughout most storm events. Even during the passage of magnetic clouds, which are defined as having a smooth rotation of the interplanetary magnetic field (IMF) [e.g., Burlaga et al., 1981], short-lived deviations are present in the solar wind conditions [see, e.g., Zhang et al., 2004]. Solar wind variations, in particular sign changes in IMF $B_{z}$, lead to sudden changes in the convection strength

\footnotetext{
${ }^{1}$ Atmospheric, Oceanic, and Space Sciences Department, University of Michigan, Ann Arbor, Michigan, USA. USA.

ISR-1, Los Alamos National Laboratory, Los Alamos, New Mexico,

${ }^{3}$ Also at Finnish Meteorological Institute, Helsinki, Finland.

Copyright 2011 by the American Geophysical Union. 0148-0227/11/2010JA015914
}

within the magnetosphere, which alters the delivery of the near-Earth plasma sheet to the inner magnetosphere to form the storm time ring current. The sheath regions of interplanetary disturbances are even more variable [e.g., Tsurutani et al., 1988], in which the ambient solar wind has been piled up in front of the fast-moving disturbance. This interval often contains many sign changes in $\mathrm{IMF}_{\mathrm{z}}$ and many large spikes in solar wind dynamic pressure $P_{\text {dyn }}$.

[4] The near-Earth plasma sheet parameters also show large, transient variations during storms. Intense storms are often accompanied by superdense plasma sheet observations [Thomsen et al., 2003; Liemohn et al., 2008], but these large density excursions are often short-lived [e.g., Borovsky et al., 1997b; Lavraud et al., 2005]. Furthermore, density fluctuations usually accompany these increases, with many dropouts in density interspersed with the superdense intervals.

[5] Recent studies have shown that earthward transport of plasma and magnetic flux in the magnetotail occurs in the form of short-duration, high-speed plasma flows, rather than as slow, steady convection. High-speed flows in the inner central plasma sheet were first reported by Baumjohann et al. [1990] and later studied in detail by Angelopoulos et al. [1992] and Sergeev et al. [1996]. Cluster 4 spacecraft observations have revealed the association of a magnetic flux rope and bursty bulk flow in the central plasma sheet [Slavin et al., 2003] as well as the connection of the evolution of the dipolarization front across the tail and the fast flow [Nakamura et al., 2002]. Several studies on dipolarization fronts were conducted using recent THEMIS data [see Runov et al., 2009]. 
[6] Observations show that substorm-associated electric fields usually display a very complicated behavior. The enhanced electric fields in the magnetotail are impulsive with amplitudes of up to $20 \mathrm{mV} / \mathrm{m}$, which is more than three times the largest convection electric field [e.g., Wygant et al., 1998], and coincident with the braking of the fast flows and correlated with the magnetic field dipolarization in the inner central plasma sheet [Tu et al., 2000, and references therein]. The question is how to account for these fast flows in the inner magnetosphere, where they are often no longer distinct transient flows but combine into an overall convective drift. Some researchers argue that convection alone can account for the ring current increase [e.g., Jordanova et al., 1998; Kozyra et al., 1998; Ebihara and Ejiri, 2003], others have concluded that especially the energization process to energies exceeding $100 \mathrm{keV}$ needs smaller-scale, timevarying electric fields [e.g., Fok et al., 1996; Ganushkina et al., 2006].

[7] An unresolved issue regarding ring current drivers is whether ring current buildup is linear or nonlinear with respect to these inputs. Ebihara et al. [2005] found a nonlinear relationship between ring current content and plasma sheet density, but Lavraud and Jordanova [2007] found a linear relationship between these parameters. Chen et al. [1993, 1994] performed ring current simulations with various levels of random spikes added to the magnetospheric convection intensity, finding that these spikes cause radial diffusion of the high-energy ions and enhance the trapped ring current during storms. Ring current simulations presented by Ganushkina et al. [2000, 2001, 2005, 2006] showed that short-lived spikes in the electric field are necessary to inject plasma sheet ions deep into the inner magnetosphere during storms. Chen et al. [2003] found that localized flow channels of high-electric field could bring plasma sheet material into the heart of the ring current in just a few minutes. Khazanov et al. [2004] conducted inner magnetospheric simulations with different time averages of electric potential distributions from the assimilative mapping of ionospheric electrodynamics (AMIE) model. They concluded that a time cadence of 5 min or more underestimate the injection and energization of the plasma sheet particles into the inner magnetosphere. Liemohn and Khazanov [2005] examined simulations of the ring current input for several storms, concluding that the best parameter that describes the adiabatic energization of the hot ions is the linear multiplication of the maximum westward electric field at the simulation outer boundary and the nightside plasma sheet density. Time integrations lessened the correlation, indicating that the energization of the ring current responds promptly to this function.

[8] Lopez et al. [2009] conducted global numerical simulations to address the question of a linear ring current response to solar wind driving. They determined that the ring current injection rate, as measured by the time variation of the Dst index, is linear with solar wind motional electric field (specifically its rectified version, VBs) even when the highlatitude response is nonlinear. Their model results show that the magnetosphere continues to shrink in size as VBs increases, and this leads to a reduction in the specific entropy of the newly created flux tubes. It has been shown that lowentropy flux tubes can more readily penetrate into the inner magnetosphere [e.g., Lemon et al., 2004; Zhang et al., 2008].
[9] More recently, Ilie et al. [2010a] performed global magnetosphere simulations with the Space Weather Modeling Framework [Tóth et al., 2005]. This study used different running averages of the solar wind upstream boundary conditions to examine the effects of transient spikes on ring current development. They found that an averaging window of less than $1 \mathrm{~h}$ did not significantly change the resulting simulated Dst time series. This implies that the magnetosphere acts as a low-pass filter regarding solar wind fluctuations and their influence on the inner magnetosphere. Longer averaging windows greatly reduced the magnetospheric response, even though the energy input to the magnetosphere was only slightly reduced by the averaging. This second result leads to the conclusion that there is a threshold lower limit of energy input needed for the magnetosphere to even create an inner magnetospheric response (i.e., a significant ring current and therefore a magnetic storm). A similar study by Ilie et al. [2010b] filtered the solar wind inputs for a high-speed stream-driven magnetic storm event, finding that the magnetosphere needs a particular signal-to-noise ratio in order to respond to periodicity in the solar wind.

[10] The issue of linear or nonlinear response of the inner magnetosphere to driving factors is also unclear when one considers linear prediction filters. Many Dst prediction schemes are linear with solar wind parameters [e.g., Burton et al., 1975; O'Brien and McPherron, 2000; O'Brien et al., 2002; Temerin and $L i, 2002,2006]$. A few, however, contain a nonlinear dependence on $\mathrm{P}_{\text {dyn }}$ [e.g., Fenrich and Luhmann, 1998; Wang et al., 2003] or the motional electric field $\mathrm{E}_{\mathrm{y}}$ [e.g., Siscoe et al., 2005].

[11] If the ring current intensity is linear with respect to its driving inputs, then the transient variations of the time series are not important by themselves. In this case, an average of the input time series should yield the same ring current intensity as those containing large fluctuations. If the ring current intensity varies nonlinearly with the driving inputs, then the transient spikes matter. In this case, an averaged time series should yield a smaller or larger ring current intensity (if the relationship is superlinear or sublinear, respectively).

[12] There has not been a conclusive study that averages both the electric field and the plasma sheet density to assess the influence of transient spikes on the development of the storm time ring current. Are the spikes important, or is the ring current caused by the cumulative input to the inner magnetosphere? This study addresses this open question of the ring current drivers by examining a particular magnetic storm event, that of 17 April 2002. It is a typical example of a relatively intense disturbance caused by the sheath of a magnetic cloud. A sheath-driven storm has many large fluctuations in the ring current input parameters, and this storm is no exception. Simulations of the ring current are conducted with various averaging and despiking windows applied to the drivers, in order to quantitatively assess the impact of the transient spikes on the development of the inner magnetospheric hot ion distribution.

\section{Approach}

[13] The magnetic storm of 17 April 2002 was a moderately intense event, reaching a Dst minimum of $-102 \mathrm{nT}$. It 
was driven by the sheath of a magnetic cloud, and was the first in a series of storms occurring over the next week. It was not the biggest of the storms in this sequence, but it was the first, so any preconditioning influences are minimized. More details of this storm are given by the papers in the special section of the Journal of Geophysical Research devoted to the April 2002 event sequence as well as elsewhere in the literature, discussing the solar heliospheric aspects of the events [e.g., Emslie et al., 2004; Hayashi et al., 2006; Zhang et al., 2007], the magnetospheric dynamics [e.g., Lui et al., 2004; Winglee et al., 2005; Henderson et al., 2006; Spencer et al., 2007; Goodrich et al., 2007; Peroomian and El-Alaoui, 2008], the plasmaspheric and ring current response of near-Earth space [e.g., Goldstein et al., 2004, 2005; Liemohn et al., 2004, 2005, 2007; Vallat et al., 2004; Kitamura et al., 2005; Chen and Sharma, 2006; Clauer et al., 2006; Ohtani et al., 2007; Kubyshkina et al., 2008; Pierrard et al., 2008; Yang et al., 2008; Buzulukova et al., 2008], and the influence on the ionosphere-thermosphere-mesosphere system [e.g., Kelley et al., 2003; Hernandez and Roble, 2003; Su et al., 2003; Mlynczak et al., 2003, 2005; Zhang et al., 2003; Anderson, 2004; Liou et al., 2005; Villante et al., 2005; Forbes et al., 2005; Goncharenko et al., 2006; Fang et al., 2007a, 2007b, 2007c].

\subsection{Numerical Model}

[14] The hot ion distribution in the inner magnetosphere during this event was simulated for this study using the Hot Electron and Ion Drift Integrator (HEIDI) model [Liemohn et al., 2005, 2006], formerly known as the Michigan version of the ring current atmosphere interaction model (RAM) developed over the last two decades [e.g., Fok et al., 1993; Jordanova et al., 1996, 1997; Liemohn et al., 2001a, 2001b, 2004]. This code solves the gyration and bounceaveraged kinetic equation for the phase space density of one or more hot plasma species as a function of time, equatorial plane radial distance, magnetic local time, energy, and equatorial pitch angle. It includes drift terms for corotation, convection, and magnetic gradient-curvature drift, as well as collision terms for Coulomb scattering and energy decay, charge exchange with the neutral hydrogen geocorona, and loss to the upper atmosphere. The wave excitation and feedback portion of HEIDI [e.g., Jordanova et al., 1997] is turned off for this study. HEIDI includes several ion species and electrons from the $\sim \mathrm{eV}$ range up to $100 \mathrm{~s}$ of $\mathrm{keV}$ in energy.

[15] The HEIDI model is coupled to several other codes as part of its normal mode of operation. For the neutral hydrogen geocorona, it uses the Rairden et al. [1986] radial profile. For the thermal plasma distribution of the plasmasphere, it simultaneously runs the dynamic global core plasma model (DGCPM) of Ober et al. [1997], which uses the same magnetic and electric field configurations as HEIDI throughout the simulation. For the ionospheric electric potential is solved self-consistently through coupling with the Ridley Ionosphere Model (RIM) [Ridley and Liemohn, 2002; Ridley et al., 2004]. This model takes a time-dependent high-latitude boundary condition from the Weimer [1996] model, the fieldaligned currents from the HEIDI solution [Liemohn et al., 2001b], and a height-integrated conductance pattern with a dynamically varying auroral oval peak as input values to a Poisson equation solution for the ionospheric potential dis- tribution. Because of this interconnection, HEIDI solves all of the species simultaneously so that the field-aligned currents passed to RIM are calculated from the pressures of all species of interest. These coupling calculations (with DGCPM and RIM) are done every time step in HEIDI. The magnetic field within HEIDI for these simulations is a static dipolar field configuration. Note that these electric and magnetic field choices do not include inductive terms from rapid field reconfigurations (e.g., substorm dipolarizations).

[16] The numerical implementation within HEIDI is similar to that of a hydrodynamic code. That is, HEIDI code is not a particle tracking kinetic model, but rather a fluid model that resolves the distribution on a grid in velocity space (rather than for moments of the velocity distribution). Typical mesh definitions for HEIDI (which are used for this study as well) are 20 cells in radial distance from $1.75 \mathrm{R}_{\mathrm{E}}$ to $6.75 \mathrm{R}_{\mathrm{E}}, 24$ cells in magnetic local time from 0 to $24 \mathrm{~h}$, 42 cells in energy from $103 \mathrm{~V}$ to $350 \mathrm{keV}$, and 72 cells in equatorial pitch angle from 0 to $90^{\circ}$. The solution, therefore, is calculated over a grid of thousands of velocity space cells at each of several hundred spatial grid cells, resulting in 1.45 million phase space density values for each species for each time step. For these simulations, HEIDI was run with $\mathrm{H}^{+}$and $\mathrm{O}^{+}$ions, the two main contributors to the total plasma pressure of the inner magnetosphere. The typical time step for HEIDI is $20 \mathrm{~s}$. It uses a conservative finite volume scheme with a Superbee flux limiter to advance the advection derivatives, and a Crank-Nicolson semi-implicit diffusion scheme for the Coulomb collision pitch angle scatter term.

\subsection{Boundary Conditions}

[17] For this study, input and boundary conditions are taken from satellite measurements. Specifically, the upstream solar wind conditions are taken from the ACE spacecraft [McComas et al., 1998; Smith et al., 1998] and the plasma sheet inputs are taken from nightside observations for the geosynchronous orbit satellites operated by Los Alamos National Laboratory (LANL), specifically from the magnetospheric plasma analyzer (MPA) instruments [Bame et al., 1993] and the synchronous orbit particle analyzer (SOPA) instruments [Belian et al., 1992]. The solar wind values are used to define a high-latitude boundary condition on the ionospheric electric potential solution. The LANL data are compiled into a single time series, taken from the satellite with the largest hot ion density among those satellites with $\pm 4 \mathrm{~h}$ of local midnight. This time series is applied everywhere across the nightside as a spatially uniform but temporally varying outer boundary condition on the HEIDI simulation domain. This is the same solar wind and plasma sheet boundary conditions applied in other recent studies using the HEIDI model to investigate the physical mechanisms at work during the 17 April 2002 storm [e.g., Liemohn et al., 2005, 2007].

[18] The upstream solar wind and nightside plasma boundary conditions are applied in several ways for this study. In addition to the standard time resolution of these input parameters, they are also smoothed with a running average window of width 20,60 , and $180 \mathrm{~min}$. The longest timescale is on par with the $3 \mathrm{~h} \mathrm{Kp}$ index, which is often used as a parameter for sorting other geophysical data or activity phenomena. The middle averaging timescale is of 


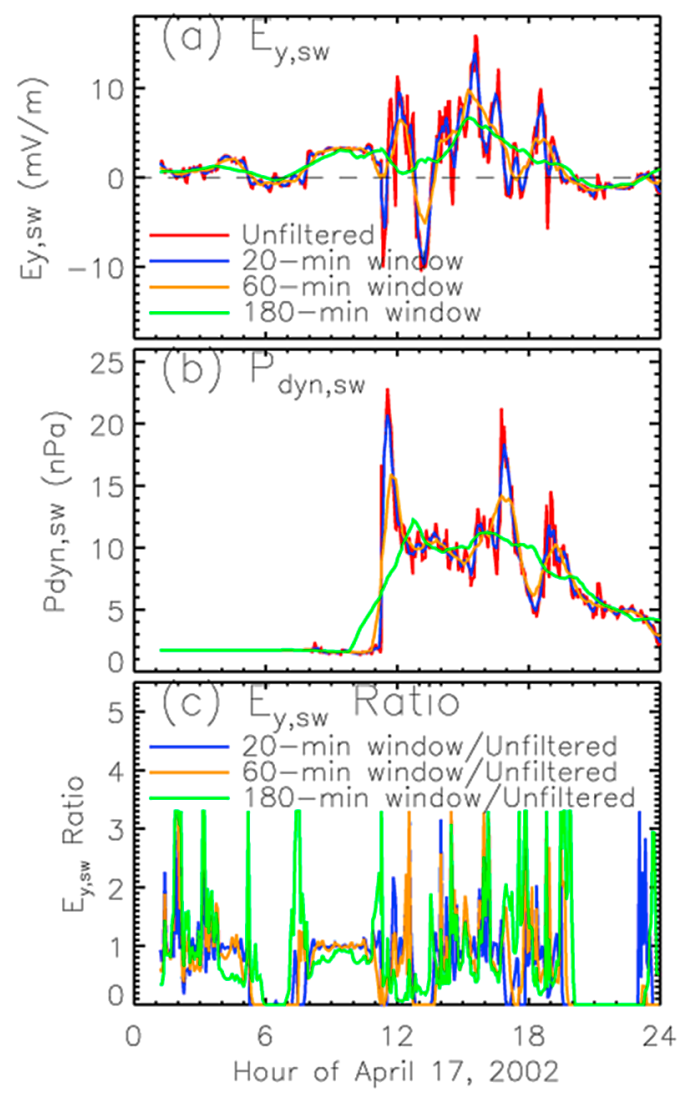

Figure 1. Four quantities from the solar wind and nearEarth plasma sheet, illustrating the effect of averaging on the time series being used as input conditions for the ring current simulations. In Figure 1c, the ratio values have been capped at 3.3 for readability.

the same cadence as the hourly Dst index, another wellknown and often-used global index derived from groundbased magnetometer data. The shortest averaged timescale is included for symmetry as a convenient interval between the real data cadence of 4 or $5 \mathrm{~min}$ and the hourly Dst cadence. The four time cadences for the input conditions to model are, therefore, essentially half an order of magnitude apart from each other.

[19] The upstream solar wind conditions during this event are shown in Figure 1. Figures 1a and 1b show the solar wind motional electric field $\mathrm{E}_{\mathrm{y}, \mathrm{sw}}$ and dynamic pressure $\mathrm{P}_{\text {dyn,sw }}$, respectively. The red line in each plot shows the measured solar wind data (Level 2 data from CDAWeb, propagated to the Earth's magnetopause) while the other various colored lines show running averages of these data in 20,60 , and $180 \mathrm{~min}$ windows. It is seen that throughout much of the second half of 17 April, $\mathrm{E}_{\mathrm{y}, \mathrm{sw}}$ was positive and $\mathrm{P}_{\mathrm{dyn}, \mathrm{sw}}$ was elevated. However, being a sheath in front of a magnetic cloud, the solar wind values include large fluctuations, including several intervals of negative $\mathrm{E}_{\mathrm{y}, \mathrm{sw}}$ (northward IMF $\mathrm{B}_{\mathrm{z}}$ ), and the dynamic pressure has several large spikes superimposed on an otherwise moderately high but typical sheath value. The smoothing technique of the running averages removes these large spikes. Figure $1 \mathrm{c}$ quantifies this for the $\mathrm{E}_{\mathrm{y}, \mathrm{sw}}$ parameter, showing the ratio of the averaged values to the unfiltered $E_{y, s w}$ values. The averaging increases $\mathrm{E}_{\mathrm{y}, \mathrm{sw}}$ in several intervals (such as, when the IMF temporarily turns northward), but also decreases it (when there is a large spike of negative IMF $B_{z}$ ).

[20] Figure 2 presents a similar set of input condition time series for the LANL nightside plasma boundary values. Figures $2 \mathrm{a}$ and $2 \mathrm{~b}$ show the composite nightside boundary condition time series' density and temperature moments. As in Figure 1, the red line shows the composite data set at its unfiltered time resolution (data from each satellite is at a 96 s cadence). The other colored lines show smoothed versions of the data with a running average window of 20 , 60 , and $180 \mathrm{~min}$. The $180 \mathrm{~min}$ averaged time series (green line) is a smooth increase in density to around $3 \mathrm{~cm}^{-3}$ at 15 UT followed by a decrease to near background levels by 21 UT. This rounded density profile is accompanied by a simultaneous and similarly smooth decrease in temperature from a prestorm value of $8 \mathrm{keV}$ down to $5 \mathrm{keV}$ at $16 \mathrm{UT}$ and back up again by the end of the day. The unfiltered time series data include many large excursions to high density values, and large, rapid temperature swings of several $\mathrm{keV}$ up or down from this running average trend. Figure $2 \mathrm{c}$ shows the ratio of the smoothed-input density time series to the unfiltered density time series. In the first half of the disturbed period (12-16 UT), the ratios can be as large as a factor of 2 ,

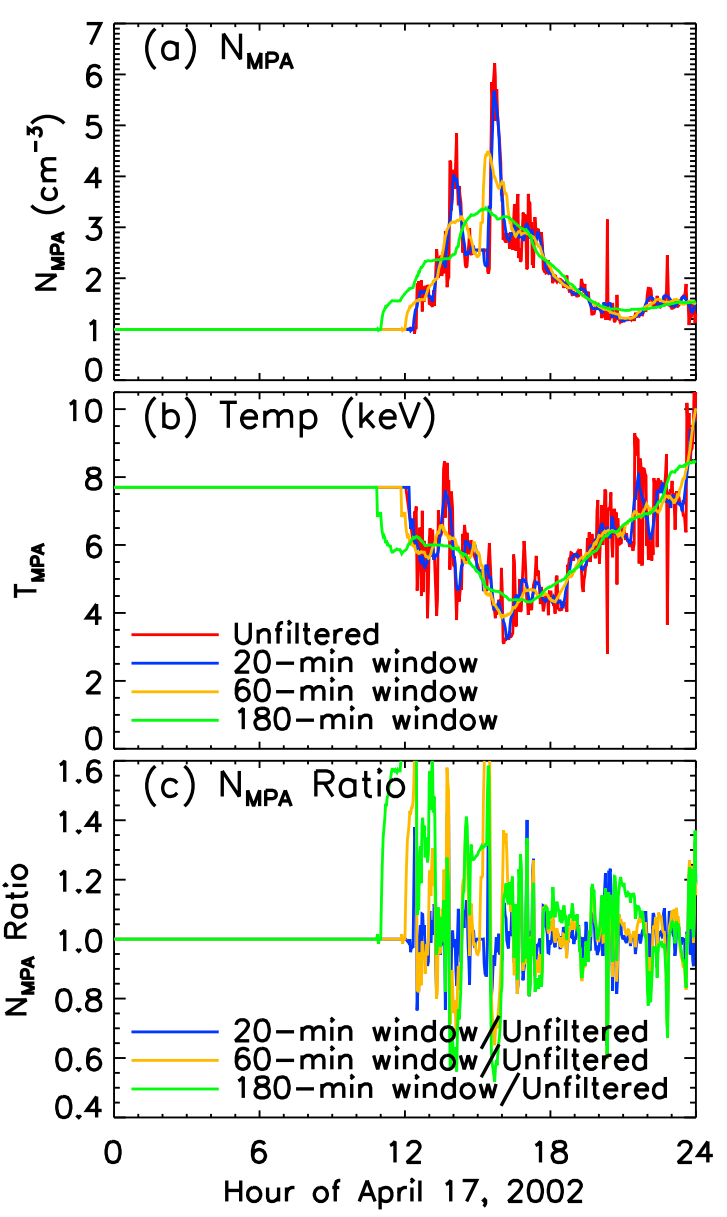

Figure 2. LANL boundary condition moments with the data averaged using a 20,60, and 180 min running window. 

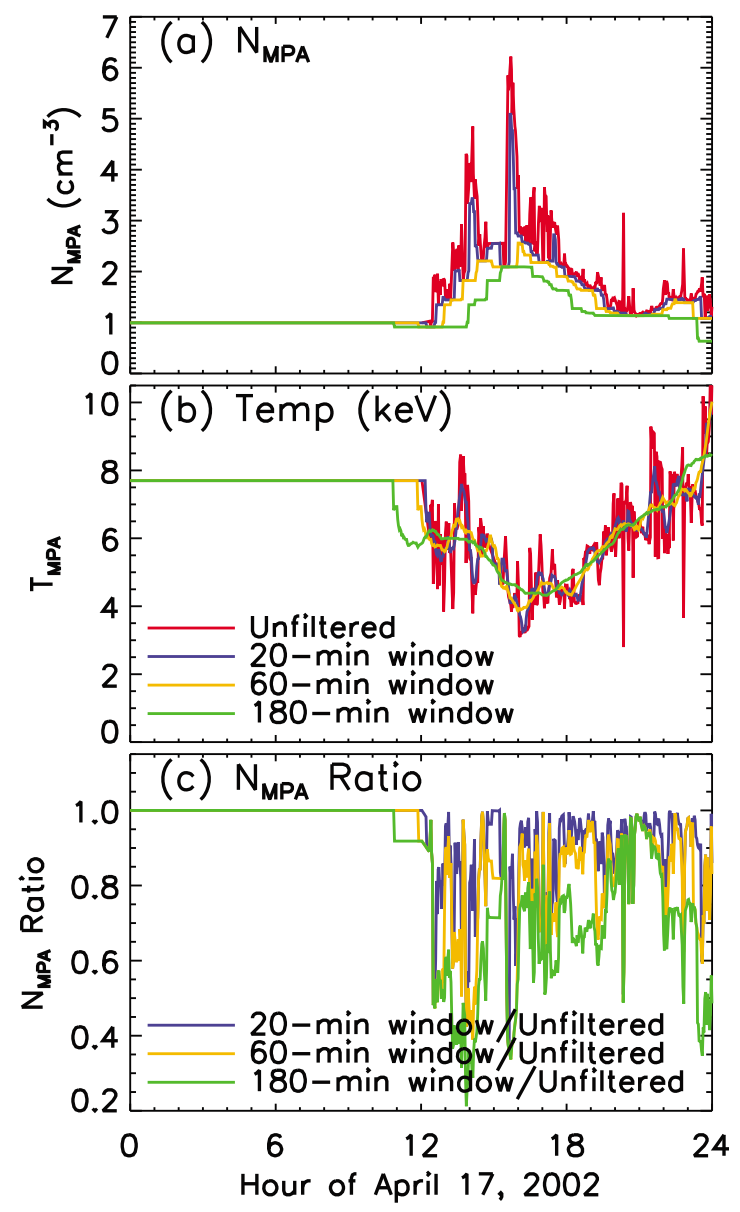

Figure 3. LANL boundary condition moments with the data despiked using a 20,60, and 180 min running window to choose the minimum value.

while the later portion of the day the ratios converge toward unity, indicating that the nightside boundary condition is similarly smooth for regardless of the averaging window.

[21] Because the nightside density is such a critical factor in the development of the ring current during magnetic storms, another set of input time series data were created to explore the influence of transient spikes. Figure 3 presents these values, in which the density moments are used to select the input values with the smallest density within a 20 , 60 , or 180 min window around a given time. Figure $3 \mathrm{a}$ shows the resulting time series. As can be seen, as the despiking window increases, the density time series reflects the lowest value within that window, sometimes maintaining a constant value for a while. Figure $3 b$ shows the resulting temperature time series from this form of input value selection. It is very similar to that in Figure 2b, when the results were averaged. Figure $3 \mathrm{c}$ is a ratios of the despiked density time series to the unfiltered density time series, illustrating that this procedure reduces the boundary condition moment by up to a factor of 5 (for the $180 \mathrm{~min}$ despiking window).

[22] To further quantify these different input conditions, it is useful to distill the time series into single numbers, providing an overall measure of the total driving for the simulation with that particular input. Because it is the convection strength and the plasma sheet density that most directly control the intensity of the storm time ring current, two integral quantities will be considered for this overall input measure. For the convection strength, the time integral of $\mathrm{E}_{\mathrm{y}, \mathrm{sw}}$ is calculated, but only a rectified version of these motional electric field time series (only when $\mathrm{E}_{\mathrm{y}, \mathrm{sw}}$ is positive). For the plasma sheet density, the time integral of the density moment of the composite nightside boundary condition is calculated. These integrals are summed over the second half of 17 April 2002, when the storm occurred. This hopefully removes any baseline shift in the integral values from the prestorm levels of these two quantities.

[23] Table 1 presents these integral quantities for the unfiltered input time series as well as the various averaged and despiked input time series. It is seen that the electric field integral drops with each successively larger window for the time average. The integral for the $3 \mathrm{~h}$ window, for instance, is nearly $30 \%$ lower than the integral for the unfiltered inputs. This is because the averaging windows include those values where Ey,sw is negative, but the time integrals presented in Table 1 are conducted over the rectified versions of the time series (because this is what matters for the magnetospheric electric field).

[24] Also in Table 1 are the ratios for the $12 \mathrm{~h}$ time integrals of the nightside boundary condition densities, both averaged and despiked. For the running-average window inputs, the ratio increases very slightly with increasing window size. Because NMPA is positive definite, one would expect these averages to be exactly equal. The small increase can be explained by the dramatic rise of the near-Earth plasma sheet density near 12 UT. The time averaged inputs are larger than the unfiltered values near this time, and the corresponding low values prior to $12 \mathrm{UT}$ are not included in the integral. The ratios for the despiking window inputs are all below unity and decrease with increasing window size, as expected. The integral for the 180 min despiking window, for example, is over $30 \%$ lower than that for the unfiltered input time series.

\section{Results}

[25] Different combinations of these smoothed and despiked input conditions are used with the HEIDI model

Table 1. Ratios of Input Value Integrals for the Averaged and Despiked Input Conditions to the Unfiltered Input Conditions Integrated From 12 to 24 UT on 17 April

\begin{tabular}{lcc}
\hline \multicolumn{1}{c}{ Time Series } & \multicolumn{2}{c}{ Ratio to Unfiltered Value Integral } \\
\hline & Integral of $E_{y, s w}$ & 0.926 \\
$20 \mathrm{~min}$ average & & 0.840 \\
$60 \mathrm{~min}$ average & 0.717 \\
$180 \mathrm{~min}$ average & \\
& Integral of Averaged $N_{M P A}$ & \\
& & 1.012 \\
$20 \mathrm{~min}$ average & & 1.051 \\
$60 \mathrm{~min}$ average & & 1.085 \\
180 min average & Integral of Despiked $N_{M P A}$ & \\
& & 0.8728 \\
$20 \mathrm{~min}$ despike & & 0.7957 \\
60 min despike & & 0.6733 \\
180 min despike &
\end{tabular}




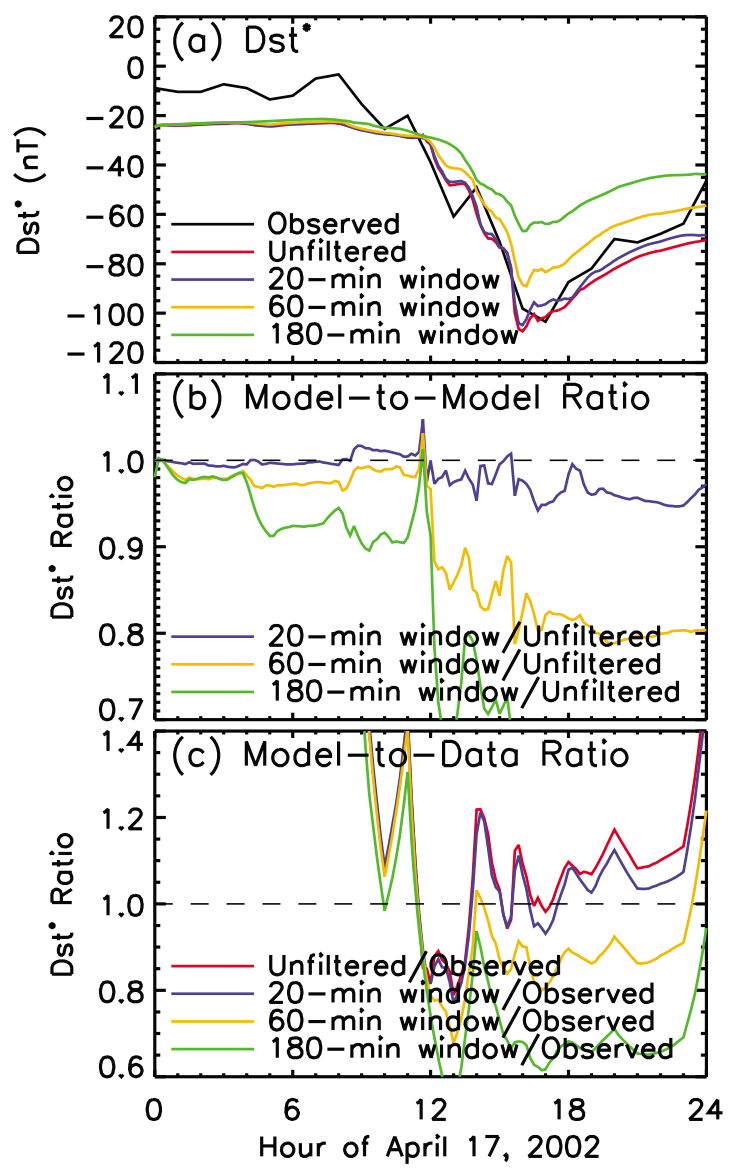

Figure 4. (a) Dst* comparison from the runs with the solar wind inputs averaged in 20, 60, and $180 \mathrm{~min}$ windows. (b) Time series of the ratio of modeled Dst* with 20, 60, and $180 \mathrm{~min}$ averaged SW inputs to that with no averaging applied. (c) Time series of the ratio of modeled Dst* to the observed Dst* time series.

to investigate the influence of the transient spikes on the development of the ring current during this storm event. The results are separated into two sections, one describing the influence of these altered boundary conditions on the total energy of the hot ions in the inner magnetosphere and another detailing the effect on the pressure distribution of these ions in near-Earth space.

\subsection{Influence on Total Energy Content}

[26] The Dessler-Parker-Sckopke (DPS) equation is a convenient formula to relate the total energy content of the inner magnetospheric hot plasma to ground-based magnetic perturbations [Dessler and Parker, 1959; Sckopke, 1966; Carovillano and Siscoe, 1973],

$$
D s t^{*}[\mathrm{nt}]=-3.98 \times 10^{-30} E_{R C}[\mathrm{keV}] .
$$

This DPS formula (1) can be directly compared against the modified Dst index, Dst*,

$$
D s t^{*}=\frac{D s t-D_{M P}+D_{Q}}{C_{I C}}
$$

in which the influence of the magnetopause currents $\left(D_{M P}\right.$, set to 8.7 times the square root of solar wind dynamic pressure) have been subtracted, induced currents within the Earth $\left(\mathrm{C}_{\mathrm{IC}}\right.$, set to 1.3$)$ have been removed, and a quiet time offset $\left(\mathrm{D}_{\mathrm{Q}}\right.$, set to $\left.11 \mathrm{nT}\right)$ has been included. Ionospheric and field-aligned current effects are minimized in Dst by averaging measurements from a worldwide chain of low-latitude stations, although sometimes they can contribute tens of nT to the index [e.g., Friedrich et al., 1999; Munsami, 2000]. The index is imperfect, but Biot-Savart magnetic perturbations from magnetospheric currents derived from in situ particle observations can account for most of the Dst variation during storms [Greenspan and Hamilton, 2000; Turner et al., 2001; Jorgensen et al., 2004]. With the modifications to Dst in the formulation of Dst*, the influence of other current systems is even smaller. Therefore, although the relationship between the Dst* index and the DPS relation is known to be flawed [e.g., Liemohn, 2003], we maintain that there is a significant link between Dst* and the ring current. Furthermore, Liemohn [2003] showed that the DPS relation includes a crude proxy for the tail current contribution to the magnetic perturbation. They found that the DPS relation assumes that all of the plasma pressure is contained within the integration volume, and therefore it implicitly includes a contribution from a "truncation current" at the outer boundary of the volume if the pressure there is nonzero. Because this is always the case when the volume only extends out to geosynchronous orbit (as in the present study), the contribution from this current is included in our DPS calculations. It is not a real current, but, in some rough manner, approximates the contribution from all pressure gradients beyond the simulation domain, and therefore approximates the contribution from the tail current at that time. Liemohn [2003] found that the contribution of this current varies with storm phase, ranging from a low of $5-10 \%$ during the late recovery phase (when the inner magnetosphere has a strong current system and the tail current is weak) to $50 \%$ during the initial part of the main phase of intense storms (when the tail current is strong but before the ring current has developed). It is certainly not perfect, but allows for the usage of the DPS relation over a finite volume with some reasonable hope of matching the globally averaged Dst* index. Therefore, in the following analysis, the total energy content of the ring current will be shown as a magnetic perturbation according to the DPS equation (1), and these results will be compared against the observed Dst* time series for the event.

[27] Figure 4 shows the total content results for the smoothed solar wind input simulations. Figure $4 \mathrm{a}$ presents the DPS relation results for the various HEIDI model runs as well as the Dst* index for this day. It is seen that the total content of the ring current decreases as the solar wind values are smoothed with a longer running-average window. It is difficult to see whether the unfiltered SW input run or the 20 min averaged SW input results are closest to the observed Dst* time series, but it is clear that the $60 \mathrm{~min}$ and $180 \mathrm{~min}$ averaged results are significantly lower in total energy content. To help quantify the similarities and differences between the model results, Figure $4 \mathrm{~b}$ presents model-to-model ratios of the DPS relation perturbation from these simulations. The smoothed input results are divided by the unfiltered input run output. It is seen that 
Table 2. Ratios of the DPS and Dst* Time Series Integrated From 12 to 24 UT on 17 April

\begin{tabular}{|c|c|c|}
\hline Simulation & $\begin{array}{c}\text { Ratio to Unfiltered } \\
\text { Value Integral }\end{array}$ & $\begin{array}{l}\text { Ratio to Observed } \\
\text { Dst* Integral Value }\end{array}$ \\
\hline Unfiltered input & 1 & 1.07 \\
\hline \multicolumn{3}{|c|}{ Smoothed Solar Wind Input Simulations } \\
\hline 20 min average & 0.97 & 1.04 \\
\hline $60 \mathrm{~min}$ average & 0.82 & 0.88 \\
\hline $180 \mathrm{~min}$ average & 0.65 & 0.69 \\
\hline \multicolumn{3}{|c|}{ Smoothed Plasma Boundary Condition Simulations } \\
\hline $20 \mathrm{~min}$ average & 1.01 & 1.09 \\
\hline $60 \mathrm{~min}$ average & 1.01 & 1.09 \\
\hline $180 \mathrm{~min}$ average & 1.07 & 1.14 \\
\hline \multicolumn{3}{|c|}{ Smoothed Solar Wind and Plasma Boundary Simulations } \\
\hline $20 \mathrm{~min}$ average & 0.95 & 1.01 \\
\hline $60 \mathrm{~min}$ average & 0.85 & 0.90 \\
\hline $180 \mathrm{~min}$ average & 0.73 & 0.77 \\
\hline \multicolumn{3}{|c|}{ Despiked Plasma Boundary Simulations } \\
\hline 20 min despike & 0.95 & 1.02 \\
\hline 60 min despike & 0.87 & 0.93 \\
\hline 180 min despike & 0.84 & 0.90 \\
\hline
\end{tabular}

the unfiltered input results are larger than the smoothed input results throughout the day, except for a brief interval right at the time of the shock impact on the magnetosphere. Figure $4 \mathrm{~b}$ shows that the $20 \mathrm{~min}$ averaged input simulation is within $5 \%$ of the unfiltered input simulation during the storm, while the other two simulations are tens of percent lower. Figure $4 \mathrm{c}$ shows a similar comparison, but with the model-to-data ratio being presented. The simulated energy content time series are larger than the observed Dst* values prior to the storm, simply because of the initial condition used for the simulations. During the storm, however, this preexisting ring current is swept away and overwhelmed by the injection of fresh ions from the near-Earth plasma sheet, and the resulting DPS relation time series are quite close to the observed Dst* time series for the unfiltered and $20 \mathrm{~min}$ averaged results.

[28] To further quantify the data-model and model-model comparisons of these smoothed input simulations, Table 2 shows the average of these ratios for the window from $12 \mathrm{UT}$ to $24 \mathrm{UT}$ on 17 April. This $12 \mathrm{~h}$ interval represents the main phase and recovery phase of this magnetic storm, but excludes the prestorm interval (which is dominated by the initial condition). Average ratio values for this $12 \mathrm{~h}$ interval for the lines plotted in Figures $4 \mathrm{~b}$ and $4 \mathrm{c}$ are listed in the top section of Table 2 (for the solar wind input simulations). It is seen that the change in the ratios as a function of runningaverage window size closely matches the decrease in integral energy input as roughly calculated from the solar wind motional electric field (shown in Table 1).

[29] Figure 5 shows the total energy content results for the simulations with smoothed outer boundary plasma distributions. It is seen in Figure 5a that all of the model results are very close to one another and to the Dst* time series during the event. Again, Figure 5b shows model-to-model ratios of the smoothed input results divided by the unfiltered input DPS time series. This plot shows that as the smoothing window is increased, the resulting ring current increases in total energy content. A particularly interesting feature to notice in Figure 5b is that the total content results with larger running average windows increase earlier than the results for the shorter running average windows (or the unfiltered input values). Figure $5 \mathrm{c}$ shows the model-to-data ratios of the simulation DPS time series divided by the observed Dst* values. As in Figure 4c, the ratios are very high prior to the storm due to the initial condition assumption, but they are all within $20 \%$ of the observed Dst* time series throughout the second half of 17 April.

[30] Table 2 includes $12 \mathrm{~h}$ averaged values of the ratios in Figures $5 \mathrm{~b}$ and $5 \mathrm{c}$, in the second section labeled plasma boundary simulations. It is seen that the average ratios for the $20 \mathrm{~min}$ and $60 \mathrm{~min}$ averaged input runs are nearly identical (producing an average value only $1 \%$ higher than the unfiltered input time series average), while the $180 \mathrm{~min}$ averaged simulation produces slightly higher results $(7 \%$ higher than the unfiltered input results). The model-model ratios are close to unity, while the mode-data ratios are about $7 \%$ larger due to the difference between the data and the unfiltered simulation results (seen in the first row of Table 2).

[31] The results for the simulations with running averages of both the solar wind and the nightside plasma boundary condition are shown in Figure 6. In general, the time series line plots in Figure 6a look a similar to those in Figure 4,

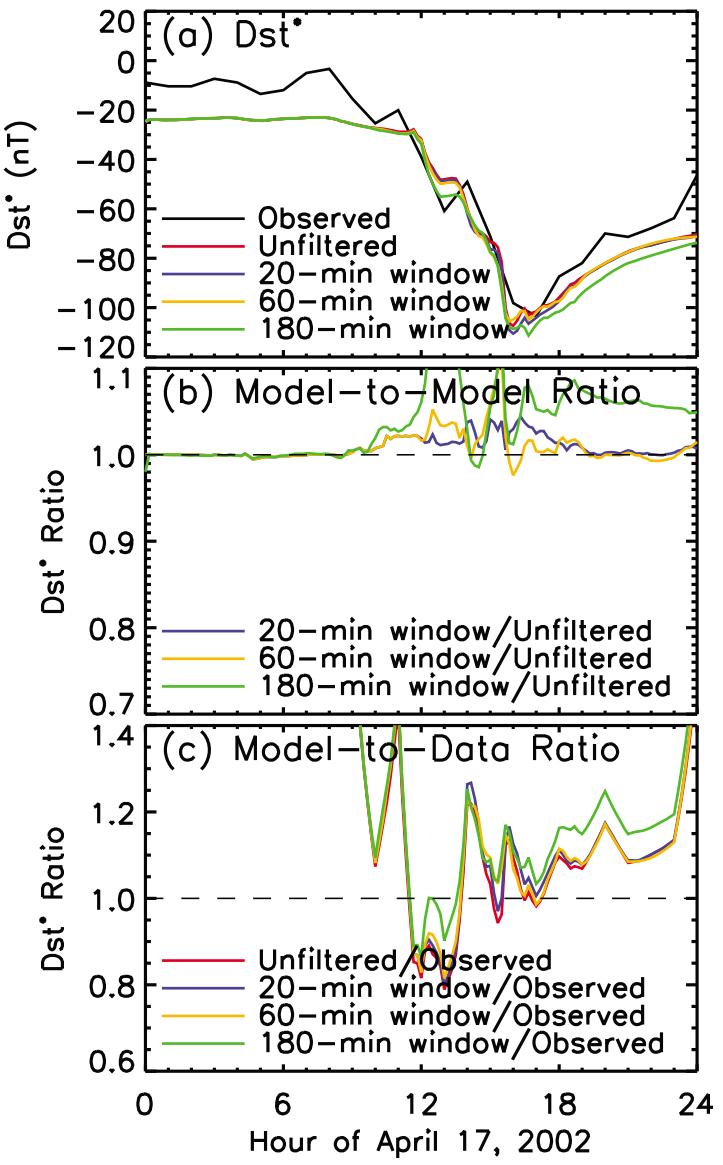

Figure 5. Same as Figure 4 except for the runs with averaged LANL nightside boundary conditions. 

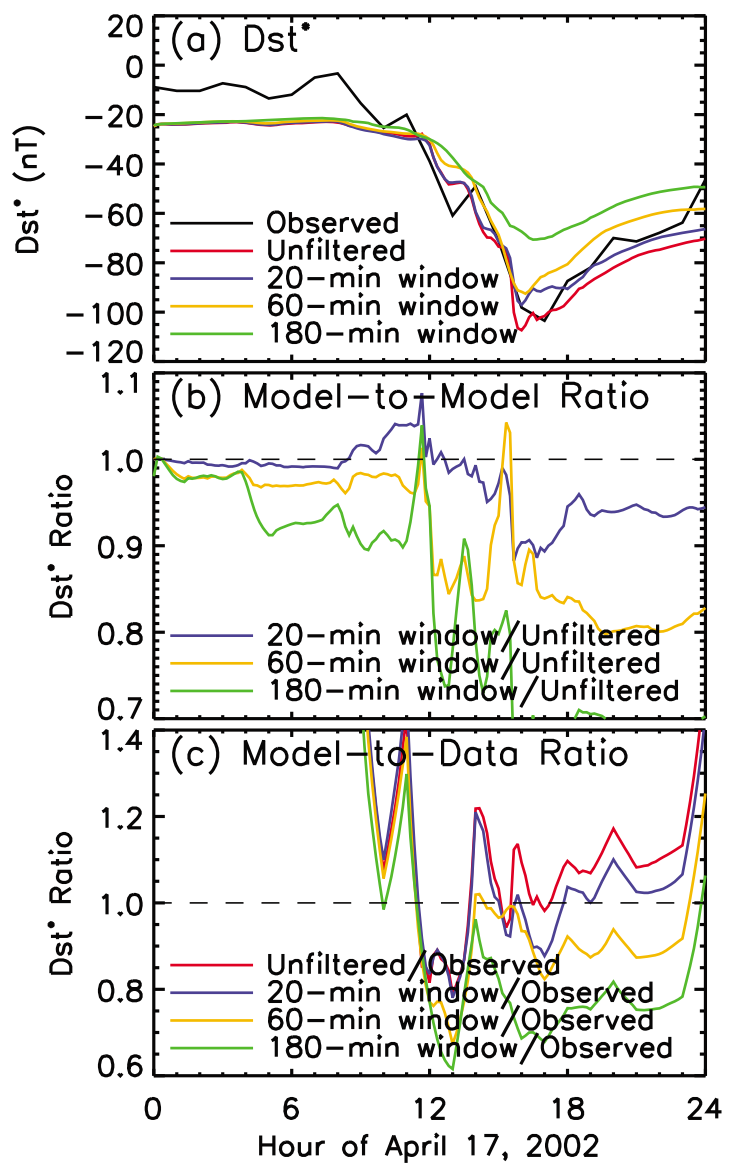

Figure 6. Same as Figure 4 except for the runs with both SW and LANL inputs averaged.

with a longer running average window yielding a lower total energy content for the ring current. Figure $6 \mathrm{~b}$ shows the model-to-model ratios of the total content time series. There are elements of both Figures $4 \mathrm{~b}$ and $5 \mathrm{~b}$ exhibited in the results shown in Figure 6b. For instance, some of the values are larger than unity early in the storm sequence (similar to Figure 5b), but then all drop well below one during the main phase and recovery phase of the storm, down to ratios similar to those seen in Figure $4 \mathrm{~b}$. Figure $6 \mathrm{c}$ shows the model-to-data ratios for these simulations. The plot has many of the same features mentioned with regard to Figures $4 \mathrm{c}$ and $5 \mathrm{c}$.

[32] The $12 \mathrm{~h}$ averages of the ratios in Figures $6 \mathrm{~b}$ and $6 \mathrm{c}$ are listed in the third section of Table 2. The numbers appear to be a multiplication of the average ratio values from the simulations with only one or the other boundary condition smoothed. That is, the numbers are slightly larger than those with only the solar wind values smoothed, by about the percentages that smoothing of the nightside plasma boundary increased the results over the unfiltered values. This is true in both the model-model ratio averages as well as the model-data ratio averages.

[33] A comparative simulation was conducted with a LANL input averaging window purely in the past, rather than centered on the time of interest. This removed the greater-than-unity values from the averaged-to-unfiltered ratios. As these simulation results and data-model comparisons do not change the main findings of the paper, these results are not shown or discussed further.

[34] The final set of simulations were those with the nightside boundary condition despiked instead of averaged. That is, the minimum value within the sliding window was applied to the simulation outer boundary rather than the average of the values within the window (as seen in Figure 3). The reductions in the resulting density should yield a substantial reduction in ring current intensity. The time series of total energy content are shown in Figure 7a. All of the simulation results still follow the general trend of the Dst* time series, and in fact all of them are relatively close to the Dst* values throughout the storm interval. Figure $7 b$ shows the model-to-model ratio values. It is seen that the total content does indeed drop, but the reductions are not as severe as those seen in Figure $4 \mathrm{~b}$ for the solar wind averaged input simulations. This is surprising because the reduction in nightside outer boundary density is actually greater than the reduction in Ey integral (listed in Table 1). Figure 7c shows the modelto-data ratio values. All of these simulations remain within $20 \%$ of the observed Dst* values nearly all of the time during the storm interval on the second half of the day.

[35] The $12 \mathrm{~h}$ averages of the ratios in Figures $7 \mathrm{~b}$ and $7 \mathrm{c}$ are listed in the bottom section of Table 2. While all of the despiked nightside input ratios are significantly lower than

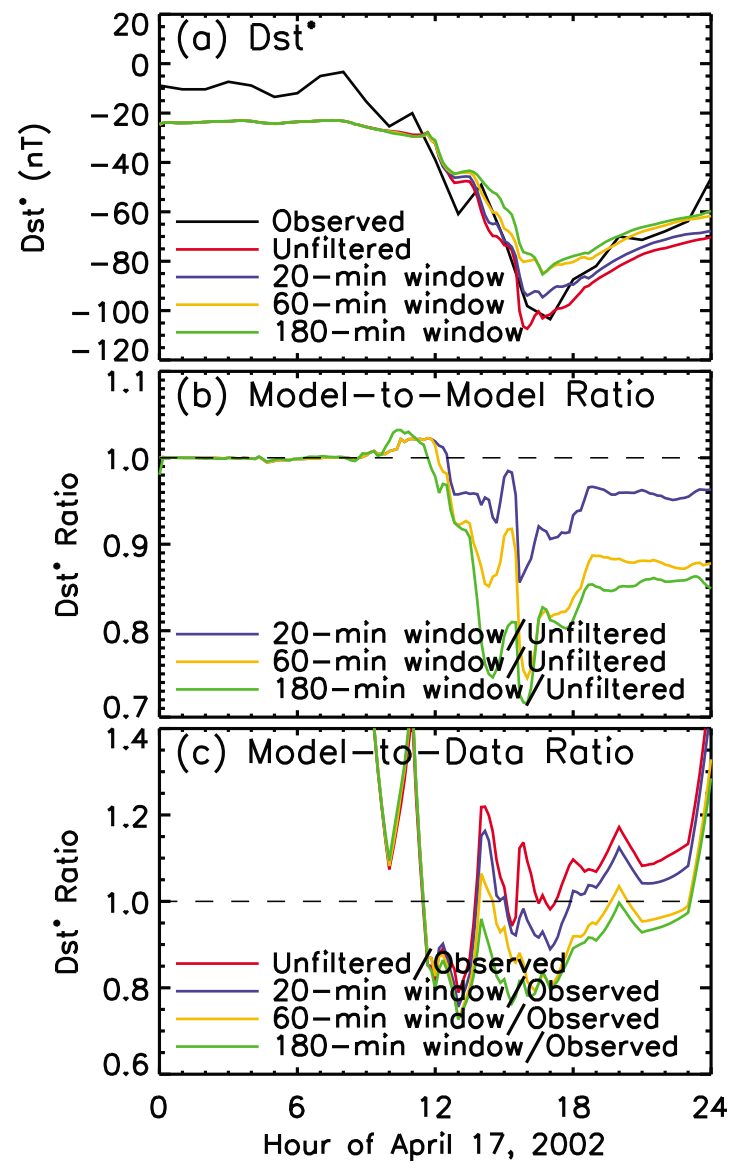

Figure 7. Same as Figure 4 except for the runs with the LANL despiked inputs. 
No averaging

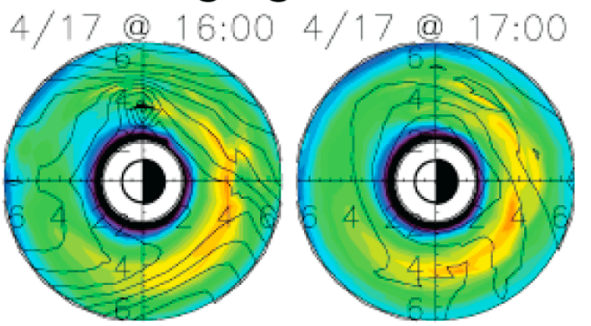

20-minute averaging

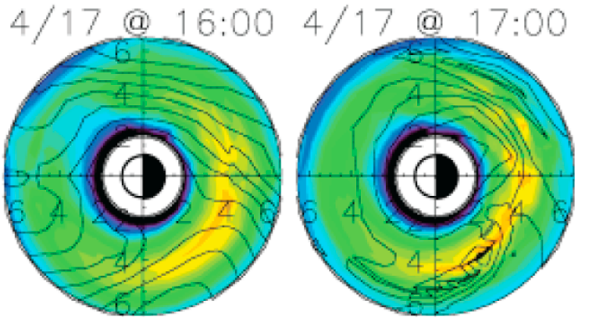

60-minute averaging

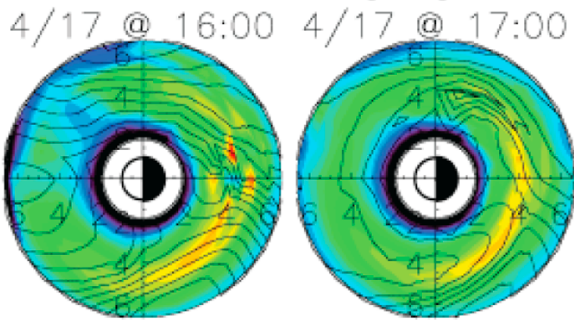

180-minute averaging

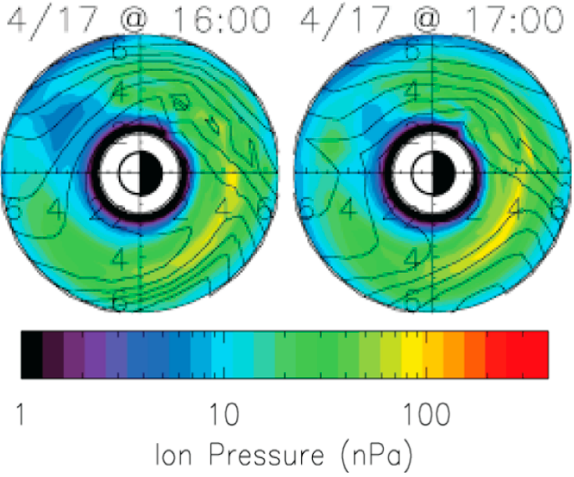

Figure 8. Modeled ion pressure in the equatorial plane from the runs with both SW and LANL inputs averaged. First row, no averaging; second row, 20 min averaging; third row, 60 min averaging; and fourth row, 180 min averaging. The left column is at $1600 \mathrm{UT}$, and the right column is at $1700 \mathrm{UT}$ (both during the main phase of the storm). Overlaid on the pressure color contours are electric potential isocontours, spaced at $8 \mathrm{kV}$ intervals.

the averaged nightside input ratios (also in Table 2), they are not as low as the despiked density ratios listed in Table 1. Furthermore, comparing the despiked nightside input ratios with those of the averaged solar wind input ratios, it is seen that the $60 \mathrm{~min}$ and $180 \mathrm{~min}$ despiked results are indeed higher than the corresponding averaged solar wind results, but that the 20 min despiked results are actually lower than the 20 min solar wind running average results, by a few percent.

\subsection{Influence on Pressure, Field-Aligned Current, and Potential Distributions}

[36] In addition to the total energy content of the ring current, it is also useful to consider the effect of smoothing the inputs on the distribution of the hot ion pressure within the inner magnetosphere. This, in turn, influences the fieldaligned currents flowing into and out of the ionosphere, and therefore the electric potential solution within the simulation domain. These three quantities (hot ion pressure, fieldaligned current, and electric potential) will be presented below. As many of these plots look rather similar, only 2 simulation result sets will be highlighted in this section: those with running averages of both the solar wind and the nightside outer boundary condition, and those with a despiked plasma outer boundary condition.

[37] Hot ion pressure distributions for the averaged input simulations (both solar wind and nightside plasma) are presented in Figure 8. Shown are 2 times during the late main phase of the magnetic storm, at 16 and 17 UT (left and right columns, respectively). The four rows are the various simulations, with the unfiltered inputs (top row) and running average windows of 20,60 , and $180 \mathrm{~min}$ (second through fourth rows, respectively). The view is over the north pole with the sun to the left, with distances in Earth radii and the outer edge of the plots being $6.5 \mathrm{R}_{\mathrm{E}}$ (close to geosynchronous orbit altitude). Note that the pressure is a summation of both $\mathrm{H}^{+}$and $\mathrm{O}^{+}$ions and that the pressure is shown on a logarithmic color scale. Superimposed over the color pressure distributions are equipotential contours at this moment in the simulation, including corotation ( $8 \mathrm{kV}$ spacing).

[38] Similar plots, except for the field-aligned currents, are shown in Figure 9 for the same times and simulations. The view is over the north pole with the currents flowing into (green-yellow-red) and out of (blue-purple) the ionosphere mapped to the equatorial plane. The color bar gives values at ionospheric altitudes, ranging from $\pm 1 \mu \mathrm{A} / \mathrm{m}^{2}$. The equipotential contours are superimposed over the fieldaligned currents (with $8 \mathrm{kV}$ spacing).

[39] As seen in previously published HEIDI simulation results with a self-consistent electric field calculation [e.g., Liemohn et al., 2005, 2006], Figure 8 shows that the inner magnetospheric hot ion plasma pressure is not smooth but rather contains significant structure. This structure is also evident in the field-aligned currents in Figure 9, which occur at the locations of pressure gradients in Figure 8. The pressure peak is not a simple kidney-bean-shaped crescent but has multiple peaks (and valleys) within a broader enhanced pressure region. The highest pressures are on the nightside during the main phase for all of the simulations, usually in the premidnight sector (often close to local midnight). This premidnight peak is clearly evident in the fieldaligned current plots, showing the peak current locations not being symmetric about midnight UT rather shifted duskward a bit. The peak is rather thin in $\mathrm{L}$ value but extended in azimuth. These simulation results indicate that the ring current is highly asymmetric during the main phase of this storm, with a pressure difference of an order of magnitude between the maximum and minimum values around the 
No averaging

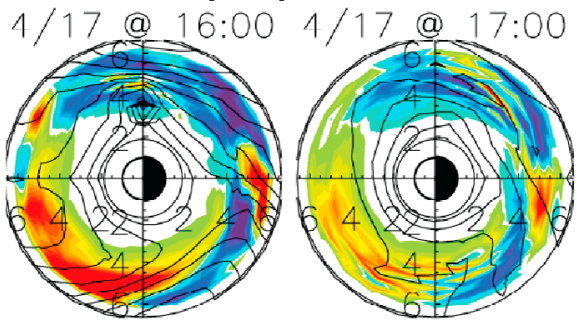

20-minute averaging

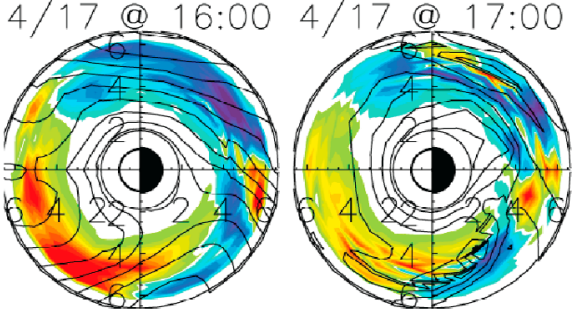

60-minute averaging

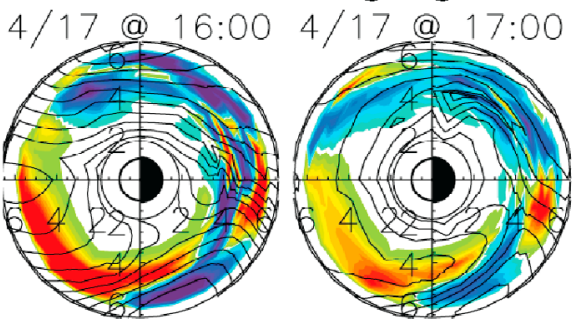

180-minute averaging

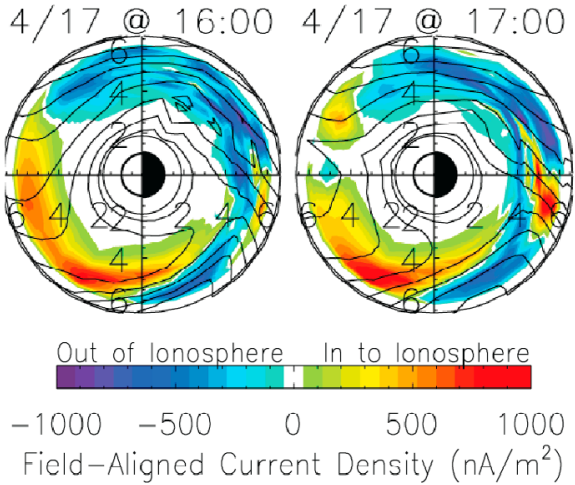

Figure 9. Modeled field-aligned currents for the same times and simulations shown in Figure 8 with both SW and LANL inputs averaged. First row, no averaging; second row, 20 min averaging; third row, 60 min averaging; and fourth row, 180 min averaging. The left column is at $1600 \mathrm{UT}$, and the right column is at 1700 UT (both during the main phase of the storm). Overlaid on the pressure color contours are electric potential isocontours, spaced at $8 \mathrm{kV}$ intervals.

high-pressure ring near $\mathrm{L}=4$. The field-aligned currents from the simulations reach values close to a $\mu \mathrm{A} / \mathrm{m}^{2}$ during the main phase.

[40] The high-pressure region is far more structured in the postmidnight sector than the premidnight sector. This is directly related to the electric field pattern that develops from the self-consistent feedback and the relationship between the field-aligned currents (closing the partial ring current) and the ionospheric conductance. The electric potential isocontours overlaid on the pressure and fieldaligned current plots reveal this highly structured electric field pattern. Closely spaced equipotentials corresponds to intense electric fields, causing rapid drifts within the inner magnetosphere. The potential wells and peaks appear as concentric circles will have electric fields pointing into or out of these locations, yielding circular flow around these places. The negative feedback process results in a disinte-

No averaging

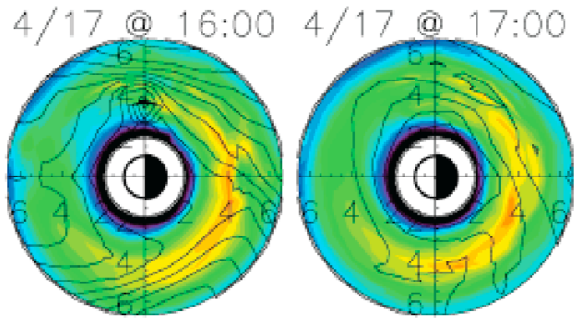

20-minute averaging

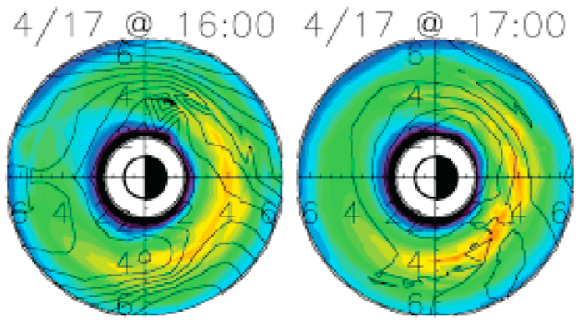

60-minute averaging

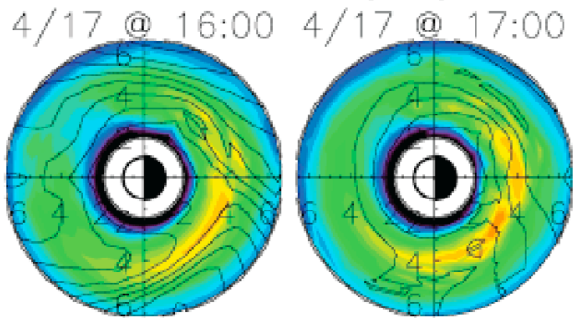

180-minute averaging
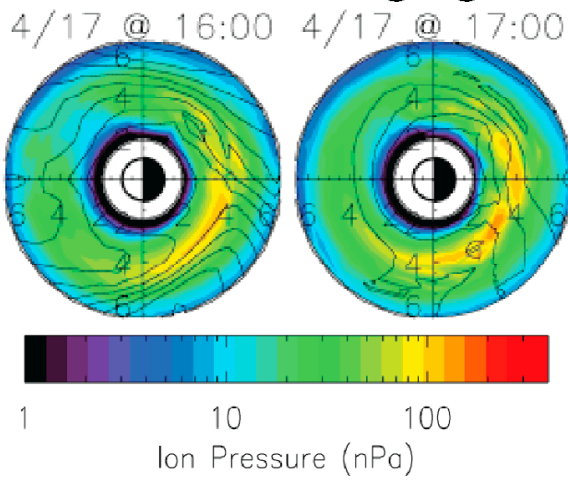

Figure 10. Equatorial plasma pressures as in Figure 8 except for the runs with despiked LANL inputs. 
No averaging
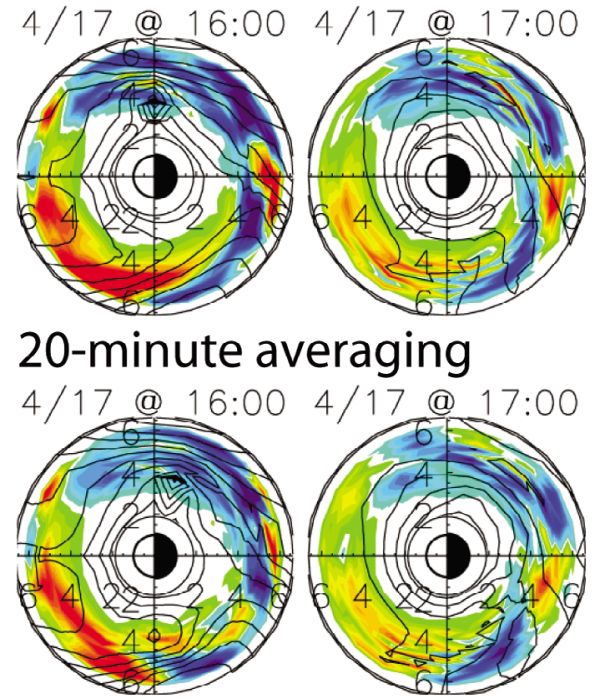

60-minute averaging

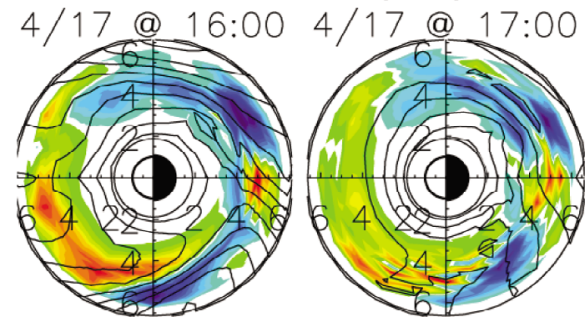

180-minute averaging

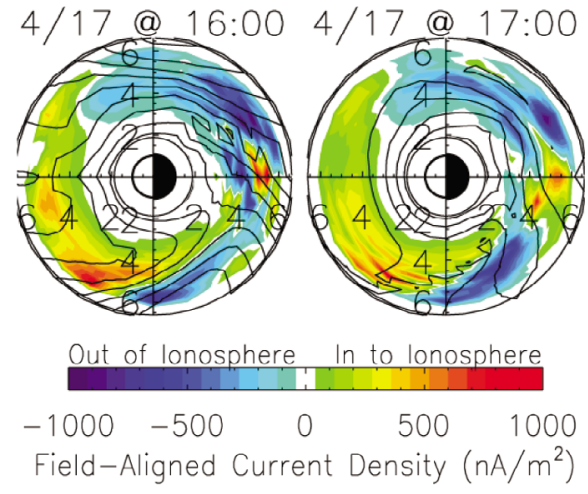

Figure 11. Field-aligned currents as in Figure 9 except for the runs with despiked LANL inputs.

gration of the pressure peak, especially in the postmidnight region, and the formation of several small pockets of high pressure. The premidnight region also shows structure but usually in the form of a wave-like pattern to the radial location of the peak.

[41] The general trend in the pressure distributions as the averaging window is increased is that the premidnight peak is reduced in intensity and the postmidnight region becomes more structured and disintegrated. It is interesting to note that the highest-pressure value on the plot is actually found in the $60 \mathrm{~min}$ averaged input simulation results at $16 \mathrm{UT}$ (third row, first column). The postmidnight feedback on and rearrangement of the pressure yields a small island of $200 \mathrm{nPa}$ pressure.

[42] Figures 10 and 11 show similar plasma pressure and field-aligned current distribution plots (with superimposed equipotential contours) for the despiked nightside boundary simulations. The general trend is that the pressure decreases with increasing size for the despiking window, but the features of the pressure distribution can vary from one simulation to another. The equipotential contours again show small-scale peaks and wells where intense electric fields rapidly redistribute the hot ions. Note that these wells and peaks are often colocated with the field-aligned currents, peak in the pressure (whether from a fresh injection or from the disintegration of an existing peak) will have a pair of field-aligned currents (and thus a potential well-peak pair) associated with it. This continual feedback between the hot ion pressure and the electric fields governing the particle motion creates a highly structured ring current in the inner magnetosphere. As in Figure 8, the highest-pressure value in Figure 10 is not in the unfiltered simulation results, but rather in the $20 \mathrm{~min}$ despiked interval result at $17 \mathrm{UT}$ (second row, second column). The peak pressure value actually occurs near the dusk terminator in a radially narrow pressure enhancement near the western end of the highpressure region.

\section{Discussion}

[43] The results presented in section 3 indicate that the response of the ring current within the HEIDI model is fairly linear to the intensity of the two primary driving parameters. Let us consider this statement, and the other implications of the plots above, in more detail, along with a comparison of these findings against those of similar studies.

\subsection{Implications of the Results}

[44] Regarding the results with the smoothed solar wind boundary conditions, the decrease in the total energy content from the HEIDI model is remarkably consistent with the decrease in integral driving function from the solar wind motional electric field. What this implies is that the ring current, as simulated by HEIDI, is responding linearly to the change in solar wind boundary condition. That is, the transient spikes in the solar wind parameters increase and decrease the overall strength of the ring current, but in a linear, not a superlinear or sublinear, relationship.

[45] A similar result is seen in the smoothed nightside plasma input simulations. The rise in the total energy content with increased running average window size is directly proportional to the rise in the average nightside density being applied to the HEIDI simulation. This rise with averaging window length can be explained when the two primary drivers of ring current intensity (source population and convective driving) are taken into account.

[46] Figure 12 shows the solar wind Ey time series overlayed on the LANL densities for each of the simulations presented in Figure 5. Note that the time interval presented in Figure 12 is shorter than that in the previous time series plots (only 9 to $17 \mathrm{UT}$ ), to focus in on the main phase of the storm interval and highlight the timing of these two driving factors. Furthermore, the $y$ axis is set to only show positive values, even though $\mathrm{E}_{\mathrm{y}, \mathrm{sw}}$ can be negative (again, to high- 

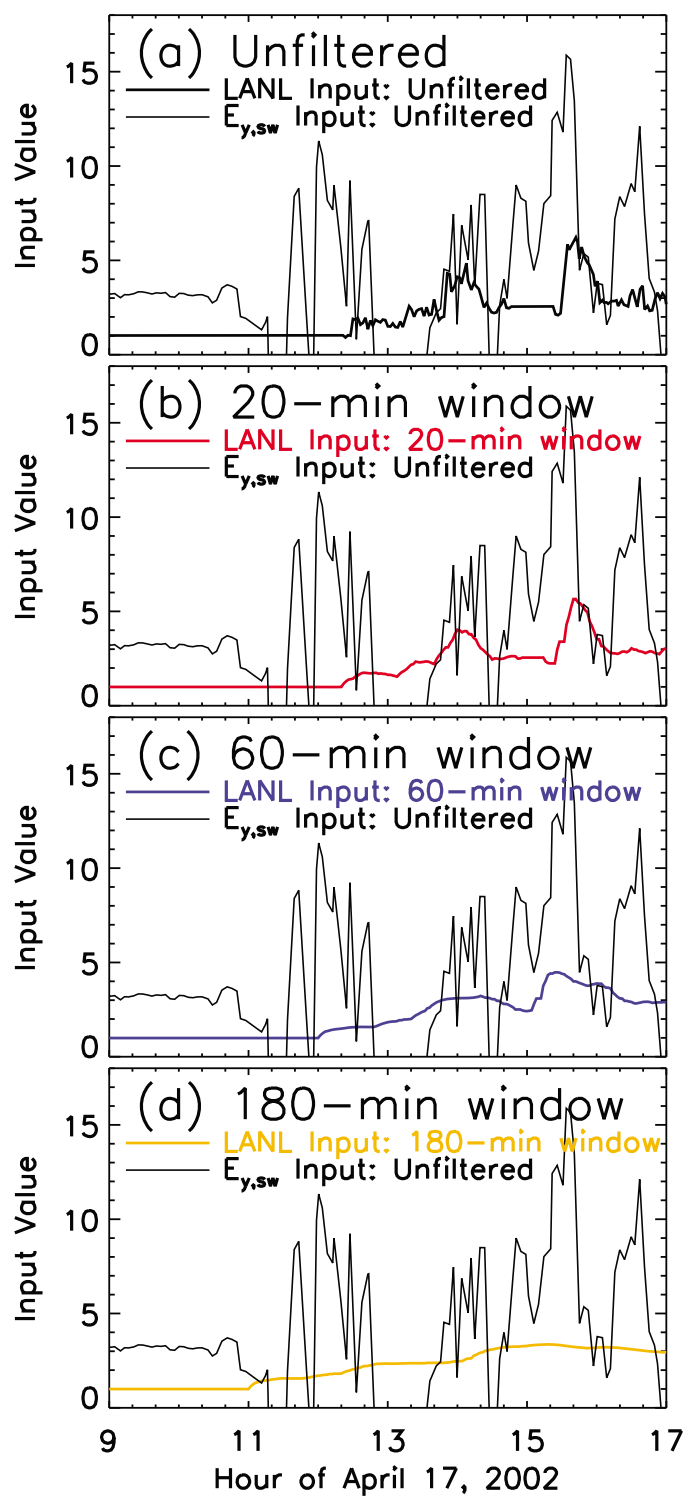

Figure 12. A close-up view of $\mathrm{E}_{\mathrm{y}, \mathrm{sw}}$ and $\mathrm{N}_{\mathrm{MPA}}$ for the LANL-averaged conditions (see Figure 5). The time interval shown is from $0900 \mathrm{UT}$ to $1700 \mathrm{UT}$ in order to focus on the main phase. The $y$ axis scale is in $\mathrm{mV} / \mathrm{m}$ for the electric field and in $\mathrm{cm}^{-3}$ for the plasma densities. Note that the $\mathrm{E}_{\mathrm{y}, \mathrm{sw}}$ values are the same in each panel.

light the times of strong driving). It is seen that the timing of the transient spikes in the plasma boundary condition time series are not perfectly aligned with the spikes in the solar wind boundary condition time series. The running-average process, however, spreads out the spikes in the plasma boundary condition, thereby increasing the plasma population intensity during the times of strong driving in the convection electric field. Therefore, the ring current intensity very slightly increases as the plasma boundary condition is spread out.

[47] A comparative simulation was conducted with a LANL input averaging window purely in the past, rather than centered on the time of interest. This removed the greater-than-unity values from the averaged-to-unfiltered ratios. As these simulation results and data-model comparisons do not change the main findings of the paper, these results are not shown or discussed further.

[48] Another point regarding the linearity of the response is that the combination of smoothing both the solar wind and nightside plasma boundary conditions yields a total energy content time series slightly greater that the results with only the solar wind input being averaged. This increase, however, is proportional the increase in the plasma sheet density increase due to the smoothing technique. Figure 13 shows the solar wind Ey time series overlayed on the LANL input conditions for the simulations presented in Figure 6. Again, it is seen that smoothing the inputs spreads out the peaks and allows the peaks in the two drivers to overlap a bit more. The fact that the simulations with smoothing in both
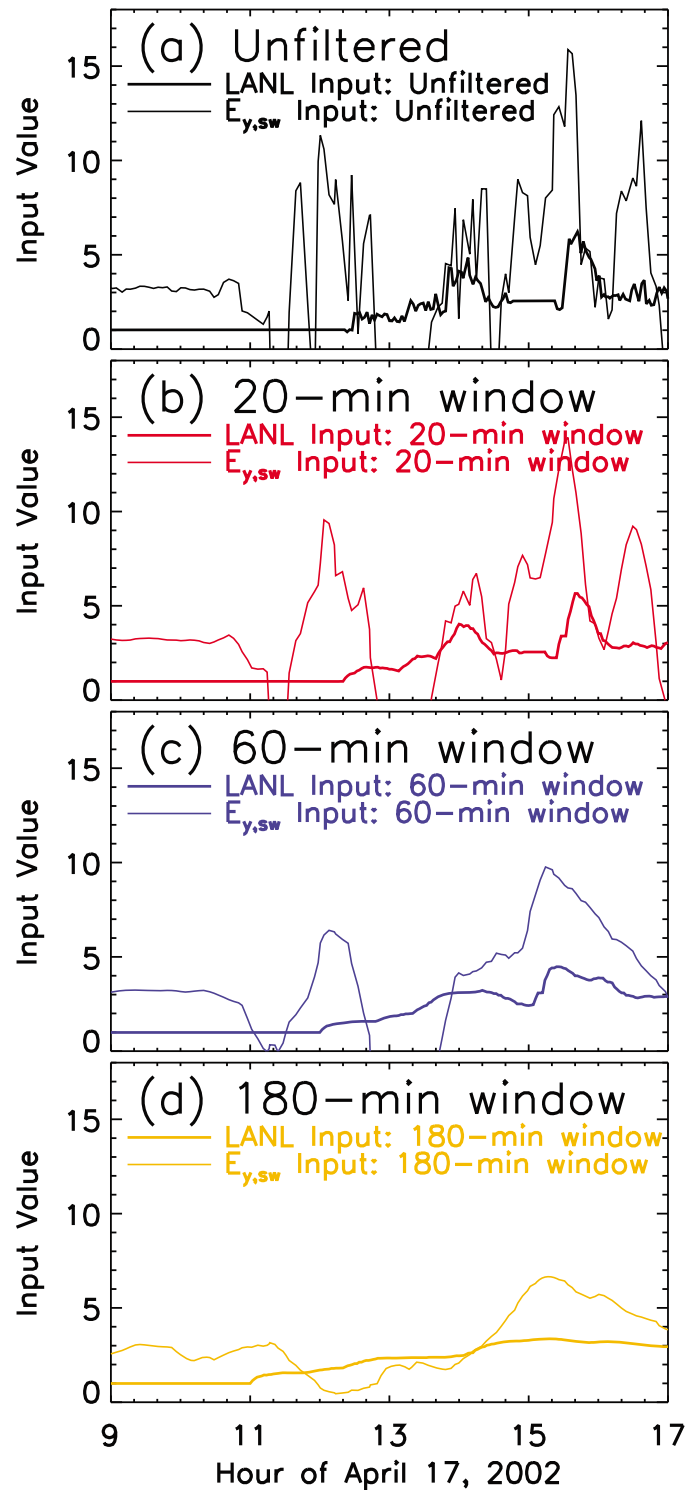

Figure 13. Same as Figure 10 but for the input conditions where both $\mathrm{E}_{\mathrm{y}, \mathrm{sw}}$ and $\mathrm{N}_{\mathrm{MPA}}$ were smoothed with running average windows. 
boundary condition parameter sets were essentially a multiplication of the averages with smoothing done separately for each of these boundary conditions implies that the ring current intensity is responding linearly to these input conditions. That is, the transient spikes are not systematically adding more or less than a simple linear summation of the driving factors forcing the growth of the ring current during this event.

[49] There is one exception to this rule of linearity in the HEIDI model response to the driver parameters. The total content results with despiked nightside plasma conditions do not follow a linear decrease in proportion to the decrease in the boundary condition density values. It appears that the $180 \mathrm{~min}$ averaged simulation produced too high of an energy content relative to the plasma density boundary condition being applied. This can be explained due to the timing of the plasma boundary enhancements relative to the strong driving intervals of large, positive $\mathrm{E}_{\mathrm{y}, \mathrm{sw}}$. It is seen that there are peaks in the unfiltered plasma density boundary condition that do not result in substantial ring current intensification because they are ill timed with the strong convection periods (which are governed by the solar wind input parameters). So, even though the HEIDI simulation results do not show a drop in total energy content that is directly proportional to the drop in the density of the nightside plasma boundary, the trend is the same and the difference with linearity can be explained.

[50] Another point to discuss in the total energy content plots is the occurrence of model-to-model ratio values greater than unity at the beginning of the storm interval. This is seen in Figures $4 b, 5 b$, and $6 b$ as a slight increase in the ratio above one near 10-12 UT. This is when the running average technique smears the arrival of the disturbance to slightly earlier times. Therefore, averaging them simply increases the solar wind driving and/or plasma density to earlier times than without this averaging and the ring current begins to develop slightly sooner.

[51] An additional issue to discuss is the variations in the plasma pressure and field-aligned current distributions seen in Figures 8, 9, 10, and 11. The change in the pressure and field-aligned current distributions as the averaging (or despiking) windows increase is due to the altered combination of the two primary driving factors for the ring current. As the relationship between the convective driving and the plasma boundary values are changed due to the averaging process, there are times when the development of the ring current is driven harder or softer. Because the existing ring current can influence the future growth of the ring current from any subsequent injections (i.e., the self-consistent electric field coupling within HEIDI), the distribution is altered as the time series for the two driving factors are smoothed. The point of highlighting the unusual pressure peak in pressure in the $60 \mathrm{~min}$ averaged simulation results is not whether this particular peak is real or not, but rather to demonstrate that the influence of changing the timing and intensity of the transient spikes in the drivers can have unexpected consequences.

\subsection{Comparison With Other Studies}

[52] The results are entirely consistent with earlier studies (like those cited in the Introduction) that found the two main drivers of the ring current to be the convection strength and the plasma sheet density. Furthermore, it confirms that the timing of high values for these two driving parameters needs to be coincident in order to yield an intense ring current.

[53] A question arises that must be addressed: how can one reconcile the findings of this study, which are that the ring current intensity responds linearly to transient spikes in the driving parameters, with the findings of Ilie et al. [2010a], who concluded that the ring current intensity responds highly nonlinearly to transient spikes in the driving parameters? Specifically, Ilie et al. [2010a] conducted whole magnetosphere simulations with the Space Weather Modeling Framework (SWMF), which includes a global magnetohydrodynamic model and an inner magnetospheric drift physics model, applying various running average windows to the upstream solar wind conditions. The result was twofold: (1) that short-window averaging (an hour or less) had essentially no influence on the eventual intensity of the near-Earth current systems (as seen in the calculated magnetic perturbation from the currents in the simulation volume); and (2) that longwindow averaging dramatically dropped the simulated Dst time series, to the point that there appeared to be a threshold energy input level to drive any significant Dst response in the model. This conclusion appears to be directly contradictory to the findings of the present study.

[54] The findings of the two studies can be reconciled by noting that Ilie et al. [2010a] considered the entire magnetosphere, applying the smoothing filter to the upstream solar wind conditions provided to the global magnetosphere model with the SWMF, while this study applies the averaging technique to the boundary conditions of a regional inner magnetospheric model. It is possible that the inner magnetosphere is responding linearly while the outer magnetosphere is not. The implication is that the nonlinearity is occurring with either the solar wind-magnetosphere coupling process and/or within processes of the magnetotail. The Ilie et al. [2010a] finding that short-average windows did not alter the resulting magnetic perturbation within the SWMF implies that the magnetosphere is acting as a low-pass filter and the highfrequency fluctuations in the solar wind do not get transferred to the inner magnetosphere. Their finding that there is a threshold for the creation of a storm time ring current implies that small-intensity driving might perturb the outer magnetosphere but may not penetrate its effects deep into the dipolar region of the magnetosphere. The results of Ilie et al. [2010a] are, therefore, consistent with the findings of this study.

[55] Liemohn et al. [2002] presented another study of relevance to the findings presented here. They found that, for the July 2000 superstorm, the ring current energy content varies proportionally to the cross polar cap potential difference, just like the present study. The nonlinearity, and indeed saturation, of the inner magnetospheric response during that superstorm was governed, then, by the nonlinear response of the high-latitude ionosphere. This augments the conclusion that the present study is consistent with the results of Ilie et al. [2010a].

[56] Similarly, the numerical approach of the present study has a simulation outer boundary at geosynchronous 
orbit. This means that the dynamics of the storm time magnetotail are not directed included or considered. The magnetotail is known to be chaotic and turbulent, especially during times of strong driving conditions. The magnetotail flows are highly irregular [e.g., Hones and Schindler, 1979], in which bursty bulk flows are regularly observed in the midtail region [e.g., Angelopoulos et al., 1994], magnetic fluctuations can reach $\Delta \mathrm{B} / \mathrm{B}$ ratios of unity [e.g., Coroniti et al., 1977; Borovsky et al., 1997a], and dipolarization injection fronts rapidly propagate Earthward [e.g., McPherron, 1973]. By taking the outer boundary of the simulation domain at geosynchronous altitude and then to not explicitly include any of these processes, we are assuming that these tail phenomena are only manifest beyond 6.6 $\mathrm{R}_{\mathrm{E}}$ and that their influences on the inner magnetosphere are fully incorporated in the electric potential and plasma boundary conditions. That is, we implicitly include magnetotail dynamics in the simulation by using high time resolution outer boundary conditions. While it is known that injection fronts can penetrate within our simulation domain [e.g., Baker et al., 2002], and others have included such injections [e.g., Li et al., 1998; Sarris et al., 2002; Ganushkina et al., 2005, 2006], these phenomena are not explicitly included in this study. However, the use of a self-consistent electric field calculation within the simulation domain means that variations in the plasma boundary conditions influence the electric field configuration within the domain, creating feedback influences that alter the plasma motion and ring current development. Induced electric fields, however, are not included in the present study.

[57] The availability of magnetospheric magnetic field models has made it possible to study the evolution of current systems during geomagnetic storms and to estimate their relative contributions to the Dst index [Ganushkina et al., 2002, 2004; Kalegaev et al., 2005]. By modeling several storm events, Ganushkina et al. [2004] have shown that the tail current intensifies first and tracks the drop in the Dst index. The ring current develops more slowly, and then stays at an increased level longer than the tail current. During moderate storms (Dst about $\sim 150 \mathrm{nT}$ ), they found that both ring and tail currents intensify but that the tail current contributes more to Dst than the ring current. On the other hand, during intense storms (Dst $\leq 200 \mathrm{nT}$ ), they found that the tail current intensifies and then remains nearly constant while the ring current follows the Dst variations. Thus, the information contained in the Dst index is different during small and large storms. Liemohn [2003] showed that the DPS relation implicitly includes a crude proxy for the tail current contribution, however, and therefore the comparisons with Dst* in this study are thought to be reasonable.

[58] Another related study is that of Ebihara et al. [2005], who conducted ring current simulations with a self-consistent electric field calculation. They found that the ring current intensity scales nonlinearly with plasma sheet density (finding something like a square root function dependence). They concluded that the self-consistent electric field acts as a limiter on the enhancement of the inner magnetospheric hot ion energy content. Liemohn and Brandt [2005] described a mechanism that could explain this nonlinearity. They showed that each pressure peak within the inner magnetosphere forms a characteristic electric potential pattern, with a potential well and peak at the eastern and western end of the pressure enhancement, respectively. This creates an outward electric field across the center of the pressure peak, acting to break it smaller pressure peaks while also limiting the injection of additional plasma from the tail. It seems then, that the findings of Ebihara et al. [2005] are inconsistent with those of the present study.

[59] Again, reconciliation is found by noting that the Ebihara et al. [2005] sublinear relationship was achieved by holding the boundary conditions of the simulation constant. That is, the sublinear dependence was reached when the inner magnetospheric response was driven toward a steady state solution. A later section of Ebihara et al. [2005] uses realistic boundary conditions, basing the plasma sheet density on solar wind density. This yielded ring current energy contents with and without electric field self-consistency that were less than $20 \%$ different, on average. In the present study, the simulation boundary conditions vary with time, and the main phase is rather short compared to the average intense storm main phase [cf., Ilie et al., 2008], so our results should also reduce the sublinear dependence of steady driving conditions. We conclude, from both our new results and the realistic input simulation from Ebihara et al. [2005], that the variations in the injection rate are faster than the response time of the inner magnetosphere to fully set up the square root dependence found by Ebihara et al. [2005]. Therefore, the two results are consistent.

[60] A final study to mention here is that of Lopez et al. [2009]. This study describes a mechanism by which the ring current does not saturate even when the cross polar cap potential does. The explanation is that the magnetosphere continues to get smaller with increasing solar wind motional electric field, which results in a continued decrease in the specific entropy of the newly created closed field lines (just inside the nightside reconnection line). The present study focuses only on plasma transport within geosynchronous orbit, using boundary conditions specified at this radial distance, and makes no claim as the source of these boundary conditions. Therefore, the two studies are certainly compatible in that they both show a linear response of the ring current under a variety of strong driving conditions.

\section{Conclusions}

[61] A numerical study was conducted to understand the role of transient spikes in the two main driving parameters that control the storm time intensity of the ring current. Two boundary conditions, the high latitude electric potential and the plasma sheet hot ion characteristics, were smoothed to remove (to different degrees) the high time resolution variations.

[62] The main conclusion is that the transient spikes linearly add to the storm time ring current energy content. When the solar wind inputs to the electric potential model were smoothed, the reductions in resulting ring current intensity were similar to the coupling function reductions due to the smoothing procedure. Time-averaging the plasma sheet characteristics made almost no difference to the resulting ring current energy content. In fact, it increased the ring current intensity slightly because it added plasma sheet density to times when the convective electric field 
were large. Plasma sheet density despiking showed a smaller decrease in the ring current content than the decrease in the boundary condition because density spikes that were originally ill timed with convection strength increases (and therefore were relatively ineffective at enhancing the ring current) had been removed, therefore skewing the otherwise linear relationship. This indicates that, at best, the relationship is linear and, if the timing of transient spikes in one driving parameter are not coincident with high values in the other main driving parameter, then the response is sublinear to those short-lived spikes.

[63] Several recent studies, however, have concluded that the ring current responds nonlinearly to the input drivers during intense storms. The conclusions of these studies were considered and the methodologies of those studies relative to the present one were compared. It was found that all of these previous studies are compatible with the results presented here, either because they were actually quantifying the nonlinear response of the outer magnetosphere or they were considering simulation results with constant driving (allowing for an equilibrium response).

[64] So, to repeat the question posed in the Introduction: are the spikes important, or is the ring current caused by the cumulative input to the inner magnetosphere? These are actually two separate questions. The answer to the latter part of the question is "yes," the storm time ring current is an accumulation of mass and energy input to the inner magnetosphere. As for the former part of the question, the answer is "no, but they help." The simulation results show that most of the ring current build up occurred even when the transient spikes were smoothed out of both driver parameters. While transient spikes are not necessary, they still can add to the eventual intensity of the ring current. That is, a larger convection electric field will push the plasma sheet ions deeper into near-Earth space and a higher plasma sheet density will create a larger ring current pressure peak.

[65] Acknowledgments. The authors would like to thank the U.S. government for sponsoring this research, in particular NASA and NSF through various research grants. Support for N.Y.G. was provided by both FMI (in particular the Academy of Finland) and U.S. sponsors. The authors also thank the Kyoto World Data Center and NASA's CDAWeb for providing access to the Dst and solar wind data.

[66] Masaki Fujimoto thanks the reviewers for their assistance in evaluating this paper.

\section{References}

Anderson, P. C. (2004), Subauroral electric fields and magnetospheric convection during the April, 2002 geomagnetic storms, Geophys. Res. Lett., 31, L11801, doi:10.1029/2004GL019588.

Angelopoulos, V., et al. (1992), Bursty bulk flows in the inner central plasma sheet, J. Geophys. Res., 97, 4027, doi:10.1029/91JA02701.

Angelopoulos, V., C. F. Kennell, F. V. Coroniti, R. Pellat, M. G. Kivelson, R. J. Walker, C. T. Russell, W. Baumjohann, W. C. Feldman, and J. T. Gosling (1994), Statistical characteristics of bursty bulk flow events, J. Geophys. Res., 99, 21,257, doi:10.1029/94JA01263.

Baker, D. N., R. E. Ergun, J. L. Burch, J.-M. Jahn, P. W. Daly, R. Friedel, G. D. Reeves, T. A. Fritz, and D. G. Mitchell (2002), A telescopic and microscopic view of a magnetospheric substorm on 31 March 2001, Geophys. Res. Lett., 29(18), 1862, doi:10.1029/2001GL014491.

Bame, S. J., et al. (1993), Magnetospheric plasma analyzer for spacecraft with constrained resources, Rev. Sci. Instrum., 64, 1026, doi:10.1063/ 1.1144173 .
Baumjohann, W., G. Paschmann, and H. Luehr (1990), Characteristics of high-speed ion flows in the plasma sheet, J. Geophys. Res., 95, 3801, doi:10.1029/JA095iA04p03801.

Belian, R. D., G. R. Gisler, T. Cayton, and R. Christensen (1992), High-Z energetic particles at geosynchronous orbit during the great solar proton event series of October 1989, J. Geophys. Res., 97, 16,897, doi:10.1029/ 92JA01139.

Borovsky, J. E., R. C. Elphic, H. O. Funsten, and M. F. Thomsen (1997a), The Earth's plasma sheet as a laboratory for flow turbulence in high[beta] MHD, J. Plasma Phys., 57, 1, doi:10.1017/S0022377896005259.

Borovsky, J. E., M. F. Thomsen, and D. J. McComas (1997b), The superdense plasma sheet: Plasmaspheric origin, solar wind origin, or ionospheric origin?, J. Geophys. Res., 102, 22,089.

Burlaga, L. F., E. Sittler, F. Mariani, and R. Schwenn (1981), Magnetic loop behind an interplanetary shock: Voyager, Helios, and IMP 8 Observations, J. Geophys. Res., 86, 6673, doi:10.1029/JA086iA08p06673.

Burton, R. K., R. L. McPherron, and C. T. Russell (1975), An empirical relationship between interplanetary conditions and Dst, J. Geophys. Res., 80, 4204, doi:10.1029/JA080i031p04204.

Buzulukova, N., M.-C. Fok, T. E. Moore, and D. M. Ober (2008), Generation of plasmaspheric undulations, Geophys. Res. Lett., 35, L13105, doi:10.1029/2008GL034164.

Carovillano, R. L., and G. L. Siscoe (1973), Energy and momentum theorems in magnetospheric processes, Rev. Geophys., 11, 289, doi:10.1029/ RG011i002p00289.

Chen, J., and A. S. Sharma (2006), Modeling and prediction of the magnetospheric dynamics during intense geospace storms, J. Geophys. Res. 111, A04209, doi:10.1029/2005JA011359.

Chen, M. W., M. Schulz, L. R. Lyons, and D. J. Gorney (1993), Storm time transport of ring current and radiation belt ions, J. Geophys. Res., 98, 3835, doi:10.1029/92JA02608

Chen, M. W., L. R. Lyons, and M. Schulz (1994), Simulations of phase space distributions of storm time proton ring current, J. Geophys. Res., 99, 5745, doi:10.1029/93JA02771.

Chen, M. W., M. Schulz, G. Lu, and L. R. Lyons (2003), Quasi-steady drift paths in a model magnetosphere with AMIE electric field: Implications for ring current formation, J. Geophys. Res., 108(A5), 1180 doi:10.1029/2002JA009584.

Clauer, C. R., X. Cai, D. Welling, A. DeJong, and M. G. Henderson (2006), Characterizing the 18 April 2002 storm time sawtooth events using ground magnetic data, J. Geophys. Res., 111, A04S90, doi:10.1029/2005JA011099.

Coroniti, F. V., F. L. Scarf, L. A. Frank, and R. P. Lepping (1977), Microstructure of a magnetotail fireball, Geophys. Res. Lett., 4, 219 doi:10.1029/GL004i006p00219.

Dessler, A. J., and E. N. Parker (1959), Hydromagnetic theory of geomagnetic storms, J. Geophys. Res., 64, 2239, doi:10.1029/JZ064i012p02239.

Ebihara, Y., and M. Ejiri (2003), Numerical simulation of the ring current: Review, Space Sci. Rev., 105, 377, doi:10.1023/A:1023905607888.

Ebihara, Y., M.-C. Fok, R. A. Wolf, M. F. Thomsen, and T. E. Moore (2005), Nonlinear impact of plasma sheet density on the storm time ring current, J. Geophys. Res., 110, A02208, doi:10.1029/2004JA010435.

Emslie, A. G., et al. (2004), Energy partition in two solar flare/CME events, J. Geophys. Res., 109, A10104, doi:10.1029/2004JA010571.

Fang, X., M. W. Liemohn, J. U. Kozyra, D. Evans, A. DeJong, and B. Emery (2007a), Global 30-240 keV proton precipitation in the 17-18 April 2002 geomagnetic storms: 1. Patterns, J. Geophys. Res., 112, A05301, doi:10.1029/2006JA011867.

Fang, X., M. W. Liemohn, J. U. Kozyra, and D. S. Evans (2007b), Global 30-240 keV proton precipitation in the 17-18 April 2002 geomagnetic storms: 2. Conductances and beam spreading, J. Geophys. Res., 112, A05302, doi:10.1029/2006JA012113.

Fang, X., A. J. Ridley, M. W. Liemohn, J. U. Kozyra, and D. S. Evans (2007c), Global 30-240 keV proton precipitation in the 17-18 April 2002 geomagnetic storms: 3 . Impact on the ionosphere and thermosphere, J. Geophys. Res., 112, A07310, doi:10.1029/2006JA012144.

Fenrich, F. R., and J. G. Luhmann (1998), Geomagnetic response to magnetic clouds of different polarity, Geophys. Res. Lett., 25, 2999, doi:10.1029/98GL51180.

Fok, M.-C., J. U. Kozyra, A. F. Nagy, C. E. Rasmussen, and G. V. Khazanov (1993), A decay model of equatorial ring current and the associated aeronomical consequences, J. Geophys. Res., 98, 19,381, doi:10.1029/ 93JA01848.

Fok, M.-C., T. E. Moore, and M. E. Greenspan (1996), Ring current development during storm main phase, J. Geophys. Res., 101, 15,311, doi:10.1029/96JA01274.

Forbes, J. M., G. Lu, S. Bruinsma, S. Nerem, and X. Zhang (2005), Thermosphere density variations due to the 15-24 April 2002 solar events 
from CHAMP/STAR accelerometer measurements, J. Geophys. Res., 110, A12S27, doi:10.1029/2004JA010856.

Friedrich, E., G. Rostoker, and M. G. Connors (1999), Influence of the substorm current wedge on the Dst index, J. Geophys. Res., 104, 4567, doi:10.1029/1998JA900096.

Ganushkina, N. Y., et al. (2000), Entry of plasma sheet particles into the inner magnetosphere as observed by Polar/CAMMICE, J. Geophys. Res., 105, 25,205, doi:10.1029/2000JA900062

Ganushkina, N. Y., T. I. Pulkkinen, V. F. Bashkirov, D. N. Baker, and X. Li (2001), Formation of intense nose structures, Geophys. Res. Lett., 28, 491, doi:10.1029/2000GL011955.

Ganushkina, N. Y., T. I. Pulkkinen, M. V. Kubyshkina, H. J. Singer, and C. T. Russell (2002), Modeling the ring current magnetic field during storms, J. Geophys. Res., 107(A7), 1092, doi:10.1029/2001JA900101.

Ganushkina, N. Y., T. I. Pulkkinen, M. V. Kubyshkina, H. J. Singer, and C. T. Russell (2004), Long-term evolution of magnetospheric current systems during storms, Ann. Geophys., 22, 1317, doi:10.5194/ angeo-22-1317-2004.

Ganushkina, N. Y., T. I. Pulkkinen, and T. Fritz (2005), Role of substorm-associated impulsive electric fields in the ring curren development during storms, Ann. Geophys., 23, 579, doi:10.5194/ angeo-23-579-2005.

Ganushkina, N., T. I. Pulkkinen, M. Liemohn, and A. Milillo (2006), Evolution of the proton ring current energy distribution during April 21-25, 2001 storm, J. Geophys. Res., 111, A11S08, doi:10.1029/2006JA011609.

Goldstein, J., B. R. Sandel, M. R. Hairston, and S. B. Mende (2004), Plasmapause undulation of 17 April 2002, Geophys. Res. Lett., 31, L15801, doi:10.1029/2004GL019959.

Goldstein, J., J. L. Burch, B. R. Sandel, S. B. Mende, P. C:son Brandt, and M. R. Hairston (2005), Coupled response of the inner magnetosphere and ionosphere on 17 April 2002, J. Geophys. Res., 110, A03205 doi:10.1029/2004JA010712.

Goncharenko, L., et al. (2006), Large variations in the thermosphere and ionosphere during minor geomagnetic disturbances in April 2002 and their association with IMF $B_{y}, J$. Geophys. Res., 111, A03303, doi:10.1029/2004JA010683

Goodrich, C. C., T. I. Pulkkinen, J. G. Lyon, and V. G. Merkin (2007) Magnetospheric convection during intermediate driving: Sawtooth events and steady convection intervals as seen in Lyon-Fedder-Mobarry global MHD simulations, J. Geophys. Res., 112, A08201, doi:10.1029/ 2006JA012155.

Greenspan, M. E., and D. C. Hamilton (2000), A test of the DesslerParker-Sckopke relation during magnetic storms, J. Geophys. Res., 105, 5419, doi:10.1029/1999JA000284.

Hayashi, K., X. P. Zhao, and Y. Liu (2006), MHD simulation of two successive interplanetary disturbances driven by cone-model parameters in IPS-based solar wind, Geophys. Res. Lett., 33, L20103, doi:10.1029/ 2006GL027408.

Henderson, M. G., G. D. Reeves, R. Skoug, M. F. Thomsen, M. H. Denton, S. B. Mende, T. J. Immel, P. C. Brandt, and H. J. Singer (2006), Magnetospheric and auroral activity during the 18 April 2002 sawtooth event, J. Geophys. Res., 111, A01S90, doi:10.1029/2005JA011111.

Hernandez, G., and R. G. Roble (2003), Simultaneous thermospheric observations during the geomagnetic storm of April 2002 from South Pole and Arrival Heights, Antarctica, Geophys. Res. Lett., 30(10), 1511, doi:10.1029/2003GL016878.

Hones, E. W., and K. Schindler (1979), Magnetotail plasma flow during substorms: A survey with IMP 6 and IMP 8 satellites, J. Geophys. Res., 84, 7155, doi:10.1029/JA084iA12p07155.

Ilie, R., M. W. Liemohn, M. F. Thomsen, J. E. Borovsky, and J. Zhang (2008), The influence of epoch time selection when doing superposed epoch analysis on ACE and MPA data, J. Geophys. Res., 113 A00A14, doi:10.1029/2008JA013241.

Ilie, R., M. W. Liemohn, and A. Ridley (2010a), The effect of smoothed solar wind inputs on global modeling results, J. Geophys. Res., 115 A01213, doi:10.1029/2009JA014443.

Ilie, R., M. W. Liemohn, J. U. Kozyra, and J. E. Borovsky (2010b), An investigation of the magnetosphere-ionosphere response to real and idealized co-rotating interaction region events through global magnetohydrodynamic simulations, Proc. R. Soc. A, 466, 3279, doi:10.1098/ rspa.2010.0074

Jordanova, V. K., L. M. Kistler, J. U. Kozyra, G. V. Khazanov, and A. F. Nagy (1996), Collisional losses of ring current ions, J. Geophys. Res., 101, 111, doi:10.1029/95JA02000.

Jordanova, V. K., J. U. Kozyra, A. F. Nagy, and G. V. Khazanov (1997), Kinetic model of the ring current-atmosphere interactions, J. Geophys. Res., 102, 14,279, doi:10.1029/96JA03699.

Jordanova, V. K., C. J. Farrugia, L. Janoo, J. M. Quinn, R. B. Torbert, K. W. Ogilvie, R. P. Lepping, J. T. Steinberg, D. J. McComas, and R. D. Belian
(1998), October 1995 magnetic cloud and accompanying storm activity: Ring current evolution, J. Geophys. Res., 103, 79, doi:10.1029/ 97JA02367.

Jorgensen, A. M., H. E. Spence, W. J. Hughes, and H. J. Singer (2004), A statistical study of the global structure of the ring current, J. Geophys. Res., 109, A12204, doi:10.1029/2003JA010090.

Kalegaev, V. V., N. Y. Ganushkina, T. I. Pulkkinen, M. V. Kubyshkina, H. J. Singer, and C. T. Russell (2005), Relation between the ring current and the tail current during magnetic storms, Ann. Geophys., 23, 523, doi:10.5194/angeo-23-523-2005.

Kelley, M. C., J. J. Makela, J. L. Chau, and M. J. Nicolls (2003), Penetration of the solar wind electric field into the magnetosphere/ionosphere system, Geophys. Res. Lett., 30(4), 1158, doi:10.1029/2002GL016321.

Khazanov, G. V., M. W. Liemohn, M.-C. Fok, T. S. Newman, and A. J. Ridley (2004), Storm time particle energization with AMIE potentials, J. Geophys. Res., 109, A05209, doi:10.1029/2003JA010186.

Kitamura, K., H. Kawano, S. Ohtani, A. Yoshikawa, and K. Yumoto (2005), Local time distribution of low and middle latitude ground magnetic disturbances at sawtooth injections of 18-19 April 2002, J. Geophys. Res., 110, A07208, doi:10.1029/2004JA010734.

Kozyra, J. U., and M. W. Liemohn (2003), Ring current energy input and decay, Space Sci. Rev., 109, 105, doi:10.1023/B:SPAC.0000007516. 10433.ad.

Kozyra, J. U., V. K. Jordanova, J. E. Borovsky, M. F. Thomsen, D. J. Knipp, D. S. Evans, D. J. McComas, and T. E. Cayton (1998), Effects of a high-density plasma sheet on ring current development during the November 2-6, 1993, magnetic storm, J. Geophys. Res., 103, 26,285, doi:10.1029/98JA01964.

Kozyra, J. U., M. W. Liemohn, C. R. Clauer, A. J. Ridley, M. F. Thomsen J. E. Borovsky, J. L. Roeder, and V. K. Jordanova (2002), Two-step Dst development and ring current composition changes during the 4-6 June 1991 magnetic storm, J. Geophys. Res., 107(A8), 1224, doi:10.1029/ 2001JA000023

Kubyshkina, M., T. I. Pulkkinen, N. Y. Ganushkina, and N. Partamies (2008), Magnetospheric currents during sawtooth events: Event-oriented magnetic field model analysis, J. Geophys. Res., 113, A08211, doi:10.1029/2007JA012983.

Lavraud, B., and V. K. Jordanova (2007), Modeling the effects of cold-dense and hot-tenuous plasma sheet on proton ring current energy and peak location, Geophys. Res. Lett., 34, L02102, doi:10.1029/ 2006GL027566.

Lavraud, B., M. H. Denton, M. F. Thomsen, J. E. Borovsky, and R. H. W. Friedel (2005), Superposed epoch analysis of dense plasma access to geosynchronous orbit, Ann. Geophys., 23, 2519, doi:10.5194/angeo-232519-2005.

Lemon, C., R. A. Wolf, T. W. Hill, S. Sazykin, R. W. Spiro, F. R. Toffoletto, J. Birn, and M. Hesse (2004), Magnetic storm ring current injection modeled with the Rice convection model and a self-consistent magnetic field, Geophys. Res. Lett., 31, L21801, doi:10.1029/ 2004GL020914.

Li, X., D. N. Baker, M. Temerin, G. D. Reeves, and R. D. Belian (1998) Simulation of dispersionless injections and drift echoes of energetic electrons associated with substorms, Geophys. Res. Lett., 25, 3763 , doi:10.1029/1998GL900001.

Liemohn, M. W. (2003), Yet another caveat to the Dessler-Parker-Sckopke relation, J. Geophys. Res., 108(A6), 1251, doi:10.1029/2003JA009839. Liemohn, M. W., and P. C. Brandt (2005), Small-scale structure in the storm time ring current, in Inner Magnetosphere Interactions: New Perspectives From Imaging, Geophys. Monogr. Ser., vol. 159, edited by J. L. Burch, M. Schulz, and H. Spence, 167 pp., AGU, Washington, D. C.

Liemohn, M. W., and G. V. Khazanov (2005), Parameterization of ring current adiabatic energization, in Particle Acceleration in Astrophysical Plasmas: Geospace and Beyond, Geophys. Monogr. Ser., vol. 156 , edited by D. Gallagher et al., 215 pp., AGU, Washington, D. C.

Liemohn, M. W., and J. U. Kozyra (2005), Testing the hypothesis that charge exchange can cause a two-phase decay, in The Inner Magnetosphere: Physics and Modeling, Geophys. Monogr. Ser., vol. 155, edited by T. I. Pulkkinen, N. Tsyganenko, and R. H. W. Friedel, 211 pp., AGU, Washington, D. C.

Liemohn, M. W., J. U. Kozyra, M. F. Thomsen, J. L. Roeder, G. Lu, J. E. Borovsky, and T. E. Cayton (2001a), Dominant role of the asymmetric ring current in producing the storm time Dst*, J. Geophys. Res., 106 , 10,883, doi:10.1029/2000JA000326.

Liemohn, M. W., J. U. Kozyra, C. R. Clauer, and A. J. Ridley (2001b) Computational analysis of the near-Earth magnetospheric current system, J. Geophys. Res., 106, 29,531, doi:10.1029/2001JA000045.

Liemohn, M. W., J. U. Kozyra, M. R. Hairston, D. M. Weimer, G. Lu, A. J. Ridley, T. H. Zurbuchen, and R. M. Skoug (2002), Consequences of a 
saturated convection electric field on the ring current, Geophys. Res. Lett., 29(9), 1348, doi:10.1029/2001GL014270.

Liemohn, M. W., A. J. Ridley, D. L. Gallagher, D. M. Ober, and J. U. Kozyra (2004), Dependence of plasmaspheric morphology on the electric field description during the recovery phase of the April 17, 2002 magnetic storm, J. Geophys. Res., 109, A03209, doi:10.1029/2003JA010304.

Liemohn, M. W., A. J. Ridley, P. C. Brandt, D. L. Gallagher, J. U. Kozyra, D. M. Ober, D. G. Mitchell, E. C. Roelof, and R. DeMajistre (2005), Parametric analysis of nightside conductance effects on inner magnetospheric dynamics for the 17 April 2002 storm, J. Geophys. Res., 110, A12S22, doi:10.1029/2005JA011109.

Liemohn, M. W., A. J. Ridley, J. U. Kozyra, D. L. Gallagher, M. F. Thomsen, M. G. Henderson, M. H. Denton, P. C. Brandt, and J. Goldstein (2006), Analyzing electric field morphology through data-model comparisons of the GEM IM/S Assessment Challenge events, J. Geophys. Res., 111, A11S11, doi:10.1029/2006JA011700.

Liemohn, M. W., J. U. Kozyra, A. J. Ridley, M. F. Thomsen, M. G. Henderson, P. C. Brandt, and D. G. Mitchell (2007), Modeling the ring current response to a sawtooth oscillation event, J. Atmos. Sol. Terr. Phys., 69, 67, doi:10.1016/j.jastp.2006.07.016.

Liemohn, M. W., J.-C. Zhang, M. F. Thomsen, J. E. Borovsky, J. U. Kozyra, and R. Ilie (2008), Superstorms at geosynchronous orbit: How different are they?, Geophys. Res. Lett., 35, L06S06, doi:10.1029/2007GL031717.

Liou, K., P. T. Newell, B. J. Anderson, L. Zanetti, and C.-I. Meng (2005), Neutral composition effects on ionospheric storms at middle and low latitudes, J. Geophys. Res., 110, A05309, doi:10.1029/2004JA010840.

Lopez, R. E., J. G. Lyon, E. Mitchell, R. Bruntz, V. G. Merkin, S. Brogl, F. Toffoletto, and M. Wiltberger (2009), Why doesn't the ring curren injection rate saturate?, J. Geophys. Res., 114, A02204, doi:10.1029/ 2008JA013141.

Lui, A. T. Y., T. Hori, S. Ohtani, Y. Zhang, X. Y. Zhou, M. G. Henderson, T. Mukai, H. Hayakawa, and S. B. Mende (2004), Magnetotail behavior during storm time "sawtooth injections," J. Geophys. Res., 109, A10215, doi:10.1029/2004JA010543

McComas, D. J., S. J. Bame, P. Barker, W. C. Feldman, J. L. Phillips, P. Riley, and J. W. Griffee (1998), Solar wind electron proton alpha monitor (SWEPAM) for the Advanced Composition Explorer, Space Sci. Rev., 86, 563, doi:10.1023/A:1005040232597.

McPherron, R. L. (1973), Satellite studies of magnetospheric substorms on August 15, 1968: 1. State of the magnetosphere, J. Geophys. Res., 78 3044, doi:10.1029/JA078i016p03044.

Mlynczak, M., et al. (2003), The natural thermostat of nitric oxide emission at $5.3 \mu \mathrm{m}$ in the thermosphere observed during the solar storms of April 2002, Geophys. Res. Lett., 30(21), 2100, doi:10.1029/2003GL017693.

Mlynczak, M. G., et al. (2005), Energy transport in the thermosphere during the solar storms of April 2002, J. Geophys. Res., 110, A12S25, doi:10.1029/2005JA011141

Munsami, V. (2000), Determination of the effects of substorms on the storm time ring current using neural networks, J. Geophys. Res., 105, 27,833, doi:10.1029/2000JA000041.

Nakamura, R., et al. (2002), Motion of the dipolarization front during a flow burst event observed by Cluster, Geophys. Res. Lett., 29(20), 1942, doi:10.1029/2002GL015763.

Ober, D. M., J. L. Horwitz, and D. L. Gallagher (1997), Formation of density troughs embedded in the outer plasmasphere by subauroral ion drift events, J. Geophys. Res., 102, 14,595, doi:10.1029/97JA01046.

O'Brien, T. P., and R. L. McPherron (2000), An empirical phase-space analysis of ring current dynamics: Solar wind control of injection and decay, J. Geophys. Res., 105, 7707, doi:10.1029/1998JA000437.

O’Brien, T. P., R. L. McPherron, and M. W. Liemohn (2002), Continued convection and the initial recovery of Dst, Geophys. Res. Lett., 29(23), 2143, doi:10.1029/2002GL015556.

Ohtani, S., et al. (2007), Cluster observations in the inner magnetosphere during the 18 April 2002 sawtooth event: Dipolarization and injection at $r=4.6 R_{E}, J$. Geophys. Res., 112, A08213, doi:10.1029/ 2007JA012357.

Peroomian, V., and M. El-Alaoui (2008), The storm time access of solar wind ions to the nightside ring current and plasma sheet, J. Geophys. Res., 113, A06215, doi:10.1029/2007JA012872.

Pierrard, V., G. V. Khazanov, J. Cabrera, and J. Lemaire (2008), Influence of the convection electric field models on predicted plasmapause positions during magnetic storms, J. Geophys. Res., 113, A08212, doi:10.1029/2007JA012612.

Rairden, R. L., L. A. Frank, and J. D. Craven (1986), Geocoronal imaging with Dynamics Explorer, J. Geophys. Res., 91, 13,613, doi:10.1029/ JA091iA12p13613.

Ridley, A. J., and M. W. Liemohn (2002), A model-derived description of the penetration electric field, J. Geophys. Res., 107(A8), 1151, doi:10.1029/2001JA000051
Ridley, A. J., T. I. Gombosi, and D. L. De Zeeuw (2004), Ionospheric control of the magnetosphere: Conductance, Ann. Geophys., 22, 567, doi:10.5194/angeo-22-567-2004.

Runov, A., V. Angelopoulos, M. I. Sitnov, V. A. Sergeev, J. Bonnell, J. P. McFadden, D. Larson, K.-H. Glassmeier, and U. Auster (2009), THEMIS observations of an earthward-propagating dipolarization front, Geophys. Res. Lett., 36, L14106, doi:10.1029/2009GL038980.

Sarris, T. E., X. Li, N. Tsaggas, and N. Paschalidis (2002), Modeling energetic particle injections in dynamic pulse fields with varying propagation speeds, J. Geophys. Res., 107(A3), 1033, doi:10.1029/ 2001JA900166.

Sckopke, N. (1966), A general relation between the energy of trapped particles and the disturbance field near the Earth, J. Geophys. Res., 71, 3125.

Sergeev, V. A., V. Angelopoulos, J. T. Gosling, C. A. Cattell, and C. T. Russell (1996), Detection of localized, plasma-depleted flux tubes or bubbles in the midtail plasma sheet, J. Geophys. Res., 101, 10,817, doi:10.1029/96JA00460.

Siscoe, G. L., R. L. McPherron, M. W. Liemohn, A. J. Ridley, and G. Lu (2005), Reconciling prediction algorithms for Dst, J. Geophys. Res., 110, A02215, doi:10.1029/2004JA010465.

Slavin, J. A., et al. (2003), Cluster electric current density measurements within a magnetic flux rope in the plasma sheet, Geophys. Res. Lett., 30(7), 1362, doi:10.1029/2002GL016411.

Smith, C. W., M. H. Acuña, L. F. Burlaga, J. L'Heureux, N. F. Ness, and J. Scheifele (1998), The ACE magnetic fields experiment, Space Sci. Rev., 86, 613, doi:10.1023/A:1005092216668.

Spencer, E., W. Horton, M. L. Mays, I. Doxas, and J. Kozyra (2007), Analysis of the 3-7 October 2000 and 15-24 April 2002 geomagnetic storms with an optimized nonlinear dynamical model, J. Geophys. Res., 112, A04S90, doi:10.1029/2006JA012019.

Su, S.-Y., C. K. Chao, H. C. Yeh, and R. A. Heelis (2003), Observations of shock impact, disturbance dynamo effect, and a midlatitude large-density depletion at $600 \mathrm{~km}$ altitude on the 17 April 2002 storm day, J. Geophys. Res., 108(A8), 1310, doi:10.1029/2002JA009752.

Temerin, M., and X. Li (2002), A new model for the prediction of Dst on the basis of the solar wind, J. Geophys. Res., 107(A12), 1472, doi:10.1029/2001JA007532.

Temerin, M., and X. Li (2006), Dst model for 1995-2002, J. Geophys. Res., 111, A04221, doi:10.1029/2005JA011257.

Thomsen, M. F., J. E. Borovsky, R. M. Skoug, and C. W. Smith (2003), Delivery of cold, dense plasma sheet material into the near-Earth region, J. Geophys. Res., 108(A4), 1151, doi:10.1029/2002JA009544.

Tóth, G., et al. (2005), Space Weather Modeling Framework: A new tool for the space science community, J. Geophys. Res., 110, A12226, doi:10.1029/2005JA011126.

Tsurutani, B. T., W. D. Gonzalez, F. Tang, S. I. Akasofu, and E. Smith (1988), Origin of interplanetary southward magnetic fields responsible for major magnetic storms near solar maximum (1978-1979), J. Geophys. Res. 93, 8519, doi:10.1029/JA093iA08p08519.

Tu, J.-N., K. Tsuruda, H. Hayakawa, A. Matsuoka, T. Mukai, I. Nagano, and S. Yagitani (2000), Statistical nature of impulsive electric fields associated with fast ion flow in the near-Earth plasma sheet, J. Geophys. Res., 105, 18,901, doi:10.1029/1999JA000428.

Turner, N. E., D. N. Baker, T. I. Pulkkinen, J. L. Roeder, J. F. Fennell, and V. K. Jordanova (2001), Energy content in the storm time ring current, J. Geophys. Res., 106, 19,149, doi:10.1029/2000JA003025.

Vallat, C., et al. (2004), First comparisons of local ion measurements in the inner magnetosphere with energetic neutral atom magnetospheric image inversions: Cluster-CIS and IMAGE-HENA observations, J. Geophys. Res., 109, A04213, doi:10.1029/2003JA010224.

Villante, U., M. Piersanti, P. Di Giuseppe, M. Vellante, T. L. Zhang, and W. Magnes (2005), Sudden commencement event of 17 April 2002: Aspects of the geomagnetic response at low latitudes, J. Geophys. Res., 110, A12S23, doi:10.1029/2004JA010978.

Wang, Y., C. L. Shen, S. Wang, and P. Z. Ye (2003), An empirical formula relating the geomagnetic storm's intensity to the interplanetary parameters: -VBz and $\Delta \mathrm{t}$, Geophys. Res. Lett., 30(20), 2039, doi:10.1029/ 2003GL017901.

Weimer, D. R. (1996), A flexible IMF dependent model of high-latitude electric potentials having "space weather" applications, Geophys. Res. Lett., 23, 2549, doi:10.1029/96GL02255.

Winglee, R. M., W. Lewis, and G. Lu (2005), Mapping of the heavy ion outflows as seen by IMAGE and multifluid global modeling for the 17 April 2002 storm, J. Geophys. Res., 110, A12S24, doi:10.1029/ 2004JA010909.

Wygant, J., D. Rowland, H. J. Singer, M. Temerin, F. Mozer, and M. K. Hudson (1998), Experimental evidence on the role of the large spatial scale electric field in creating the ring current, J. Geophys. Res., 103, 29,527, doi:10.1029/98JA01436. 
Yang, J., F. R. Toffoletto, R. A. Wolf, S. Sazykin, R. W. Spiro, P. C. Brandt, M. G. Henderson, and H. U. Frey (2008), Rice Convection Model simulation of the 18 April 2002 sawtooth event and evidence for interchange instability, J. Geophys. Res., 113, A11214, doi:10.1029/ 2008JA013635.

Zhang, J., et al. (2007), Solar and interplanetary sources of major geomagnetic storms (Dst $\leq-100 \mathrm{nT}$ ) during 1996-2005, J. Geophys. Res., 112, A10102, doi:10.1029/2007JA012321.

Zhang, J.-C., M. W. Liemohn, J. U. Kozyra, B. J. Lynch, and T. H. Zurbuchen (2004), A statistical study on the geoeffectiveness of near-Earth magnetic clouds during high solar activity years, J. Geophys. Res., 109, A09101, doi:10.1029/2004JA010410.

Zhang, J.-C., R. Wolf, A. Sazykin, and S. Toffoletto (2008), Injection of a bubble into the inner magnetosphere, Geophys. Res. Lett., 35, L02110, doi:10.1029/2007GL032048.
Zhang, S. P., J. E. Salah, N. Mitchell, W. Singer, Y. Murayama, R. R. Clark, A. van Eyken, and J. Thayer (2003), Responses of the mesospheric wind at high latitudes to the April 2002 space storm, Geophys. Res. Lett., 30(23), 2225, doi:10.1029/2003GL018521.

J. E. Borovsky, R. Ilie, and M. F. Thomsen, ISR-1, Los Alamos National Laboratory, Mail Stop D466, Los Alamos, NM 87545, USA.

N. Y. Ganushkina, J. U. Kozyra, M. W. Liemohn, and A. J. Ridley, Atmospheric, Oceanic, and Space Sciences Department, University of Michigan, 2455 Hayward St., Ann Arbor, MI 48109-2143, USA. (liemohn@umich.edu) 